\title{
Morphology and Evolution of Sesamoid Elements in Bats (Mammalia: Chiroptera)
}

Author(s): http://orcid.org/0000-0002-7292-3256Lucila Inés Amador, Norberto Pedro Giannini, http://orcid.org/0000-0001-8807-7499Nancy B. Simmons and http:// orcid.org/0000-0002-4615-5011Virginia Abdala

Source: American Museum Novitates, (3905):1-40.

Published By: American Museum of Natural History

https://doi.org/10.1206/3905.1

URL: http://www.bioone.org/doi/full/10.1206/3905.1

BioOne (www.bioone.org) is a nonprofit, online aggregation of core research in the biological, ecological, and environmental sciences. BioOne provides a sustainable online platform for over 170 journals and books published by nonprofit societies, associations, museums, institutions, and presses.

Your use of this PDF, the BioOne Web site, and all posted and associated content indicates your acceptance of BioOne's Terms of Use, available at www.bioone.org/page/terms_of_use.

Usage of BioOne content is strictly limited to personal, educational, and non-commercial use. Commercial inquiries or rights and permissions requests should be directed to the individual publisher as copyright holder. 


\title{
AMERICAN MUSEUM NOVITATES
}

Number 3905,38 pp.

August 17, 2018

\section{Morphology and Evolution of Sesamoid Elements in Bats (Mammalia: Chiroptera)}

\author{
LUCILA INÉS AMADOR, ${ }^{1}$ NORBERTO PEDRO GIANNINI, ${ }^{1,2,3}$ \\ NANCY B. SIMMONS, ${ }^{2}$ AND VIRGINIA ABDALA ${ }^{4}$
}

\begin{abstract}
Sesamoids are skeletal elements found within a tendon or ligament as it passes around a joint or bony prominence. Here we review the distribution of sesamoids in bats, the only mammals capable of powered flight. Our survey included bat species representing most extant families as well as two key Eocene fossil bats in which sesamoids are exquisitely preserved, Onychonycteris finneyi and Icaronycteris index. We identified 46 separate sesamoid elements (or sets of elements) from dissections of selected bat taxa, with no more than 23 of these present in any given species. Among the sesamoids identified in our survey, 12 have not previously been described in bats. We also identified seven sesamoids previously described in the literature that are not present in our sample of species. No sesamoids were found to be exclusive to the fossil taxa in our study; all the sesamoids observed in Onychonycteris and Icaronycteris have apparent homologs among extant species. We mapped the presence/absence of the 46 sesamoids onto a bat phylogeny. Based on these optimizations, we discuss homology issues and evolutionary history of some of the most taxonomically widespread sesamoids. Functional inferences regarding some sesamoids can be made based on what is known about bat musculoskeletal morphology, although further biomechanical studies are required to test the hypotheses proposed here. Sesamoids will continue to be a source of interesting insights about the evolution of bats and their unique locomotor abilities.
\end{abstract}

${ }^{1}$ Unidad Ejecutora Lillo: Fundación Miguel Lillo - CONICET, Tucumán, Argentina.

${ }^{2}$ Facultad de Ciencias Naturales e Instituto Miguel Lillo, Universidad Nacional de Tucumán, Tucumán, Argentina.

${ }^{3}$ Division of Vertebrate Zoology (Mammalogy), American Museum of Natural History.

${ }^{4}$ Instituto de Biodiversidad Neotropical: Universidad Nacional de Tucumán - CONICET, Tucumán, Argentina. 


\section{INTRODUCTION}

Sesamoids are typically defined as bones found within a tendon or ligament as it passes around a joint or bony prominence (Retterer and Lelièvre, 1911; Pearson and Davin, 1921a, 1921b; Romer, 1956; Haines, 1969; Le Minor, 1987; Sarin et al., 1999; Maisano, 2002; Jerez et al., 2010; Vera et al., 2015; Regnault et al., 2016). However, ossification is not essential; more broadly speaking, sesamoids are "any organized, intratendinous/intraligamentous structures, including those composed of fibrocartilage" (Regnault et al., 2017: 2; see also Haines, 1969; Tsai and Holliday, 2011). Sesamoids occur in tendons associated with a large number of mobile joints in vertebrates, most commonly in the postcranium (e.g., Romankowowa, 1961; Ponssa et al., 2010; Jerez et al., 2010; Chadwick et al., 2014; Regnault et al., 2014; Reyes-Amaya et al., 2017; Samuels et al., 2017) but also in the cranium of some taxa including many bony fishes (e.g., Alexander, 1967; Adriaens and Verraes, 1998), crocodiles and turtles (Tsai and Holliday, 2011), birds (Hall, 2005), and lizards (Montero et al., 2017). Although the study of sesamoids has been neglected historically, these structures are a source of several acute clinical problems in animals, including humans, significantly impairing proper musculoskeletal function when abnormally developed or diseased (Skillern, 1915; Bizarro, 1921; Gunn, 1928; Streatfeild and Griffiths, 1934; Sindberg, 1940; Stener, 1963; Helal, 1981; Wood, 1984; Goldberg and Nathan, 1987; Hansen and Peterson, 1987; McBryde and Anderson, 1988; Gibeault et al., 1989; Bianchi et al., 1993; Richardson, 1999; Mellado et al., 2003; Mittlmeier and Haar, 2004; DeCamp, 2016).

The best-known sesamoid is the patella (= kneecap), which is located in the primary extensor tendon associated with the knee joint in many but not all tetrapods (Reese et al., 2001; Samuels et al., 2017). The patella is absent as a bony structure in several groups of reptiles and amphibians, most marsupial mammals, and in a few species of birds and eutherian mammals, but it is present as a fibrocartilage structure in many of these taxa (e.g., Smith et al., 1995; Chadwick et al., 2014; Samuels et al., 2017; Abdala et al., 2017). In contrast, the ulnar patella, a sesamoid associated with one of the primary joints (sensu Pomikal and Streicher, 2010) of the forelimb-the elbow-is apparently normally present among mammals only in bats (Gunn, 1928; Haines, 1940; Mittal et al., 2014). Jerez et al. (2010) proposed a classification of sesamoids based on their relationships to the tendons and joints with which they are associated. The patellae (both the kneecap and the ulnar patella of bats) constitute examples of "embedded sesamoids" that are intimately associated with tendons, being entirely surrounded by tendinous tissue. Some of the most powerful muscles of the limbs (e.g., the quadriceps) with tendons wrapping around bony prominences or joints are associated with embedded sesamoids (Jerez et al., 2010). Other categories identified by Jerez et al. (2010) include "supporter sesamoids" that serve as muscle-attachment areas (e.g., the pisiform), and "glide sesamoids" that provide smooth gliding surfaces for the flexor tendons in manus and pes.

The functions of sesamoids have been a matter of speculation for decades. Sesamoids have generally been thought to function in association with the mechanical stress exerted on tendons as they wrap around a bony edge or a joint, possibly improving the ability of these tendons to respond to compressive load, pressure, tensile strain, and vibration (Carlsöö, 1982; Pearson and Davin, 1921a, 1921b; Nussbaum, 1982; Sarin et al., 1999; Jerez et al. 2010; Ponssa et al., 2010; Tsai and Holliday, 2011; Otero and Hoyos, 2013; Regnault et al., 2016; Abdala et al., 2017; Zhang et al., 2017). 
Enhanced or improved function may also be achieved by altering the moment arm of the related tendon, thus increasing the mechanical advantage of the muscle-tendon unit (Alexander and Dimery, 1985; Vickaryous and Olson, 2007; Regnault et al., 2014). Evans and De Lahunta (2013) summarized three primary potential functions of sesamoids: (1) to protect tendons that pass over bony prominences; (2) to increase the surface area for attachment of tendons over certain joints; and (3) to redirect the pull of tendons so that greater effective force can be applied to the part being moved. It is possible and indeed likely that at least some sesamoids have multiple functions, acting in different ways during different phases of locomotion, e.g., the human patella may play a different role during standing than it does during active limb extension (Mottershead, 1988).

A controversial subject has been the development of sesamoids, and how this relates to their evolutionary origins. Many authors have assumed that sesamoids form de novo within tendons in response to stresses associated with joints (e.g., Müller and Wagner, 1991; Newman and Müller, 2000; Müller, 2003). Alternatively, other authors have emphasized a potential link between epiphyses and sesamoids. Parsons (1904) first proposed the concept of "traction epiphyses," an idea subsequently supported by Barnet and Lewis (1958) and other authors (e.g., Hogg, 1980; Hutchinson, 2002; Hall, 2005; Vickaryous and Olson, 2007; Ponssa et al., 2010; Regnault et al., 2014) as an explanation for the origin of some epiphyses in tetrapods. The traction-epiphysis hypothesis suggests that preexisting intratendinous sesamoids could fuse to the end of a long bone and become part of the epiphysis. Conversely, Pearson and Davin (1921a, 1921b) proposed a reverse process in which sesamoids originate from bone processes that become separated from the main bone. Recent studies using new histological and molecular data in mammalian taxa (e.g., Koyama et al., 2010; Eyal et al., 2015) have suggested that different developmental pathways may apply to sesamoids (or sets of sesamoids) associated with different joints, and that multiple pathways related to sesamoid development hence might cooccur in the same organism.

Bats (order Chiroptera) are the only mammals capable of powered flight (Norberg and Rayner, 1987). In all mammals that use aerial locomotion (i.e., gliders and powered flyers), the airfoil consists of skin membranes known as patagia that minimally extend between the fore- and hind limbs (Norberg, 1972). In bats, airfoil area is increased by the presence of the dactylopatagium (= handwing) consisting of interdigital membranes supported by elongated fingers (e.g., Sears et al., 2006; Hockman, et al., 2008). This highly derived forelimb structure is accompanied by the modification of many muscles of the forearm and hand into largely tendinous structures that are often associated with sesamoids, especially near their points of insertion (Vaughan, 1959; Romankowowa, 1961; Norberg, 1972; this study). Sesamoids are numerous in bats and their association with the flight apparatus has intrigued researchers for over 100 years; as a result, bats have been highlighted in many studies of sesamoids (e.g., Parsons, 1904; Haines, 1940; Oxnard, 1971; Alexander and Dimery, 1985; Le Minor, 1994; Bland and Ashhurst, 1997). Bat sesamoids have also been described in the context of anatomical studies of both extant and fossil bat taxa (Macalister, 1872; Vaughan, 1959; Romankowowa, 1961; Cypher, 1996; Walton and Walton, 1970a, 1970b; Norberg, 1972; Simmons and Geisler, 1998; Simmons et al., 2008; Panyutina et al., 2015; Reyes-Amaya et al. 2017). However, studies dealing exclusively with bat sesamoids are scarce and largely have centered on the distal wing (Romankowowa, 1961; Cypher, 1996). An orderwide review of sesamoid structures across the entire 
bat skeleton is lacking. To address this gap in our understanding, in this study we present a systematic review of bat sesamoids including new data on several sesamoids not previously described in Chiroptera. Our goals were to provide a review of the previous literature on bat sesamoids, to survey the postcranial sesamoids across bat families, and to assess the evolutionary history of selected sesamoids or sesamoid traits that vary interspecifically and may have important functions relevant to various flight modes. We included in our analysis data on sesamoids from two exquisitely preserved bat fossils, Icaronycteris index (Jepsen, 1966) and Onychonycteris finneyi (Simmons et al., 2008), which together with our data on representative extant taxa, allow us to infer patterns of acquisition and loss of sesamoids in Chiroptera.

\section{MATERIALS AND METHODS}

In order to compile a list of the postcranial sesamoids thus far described for bats, we reviewed the literature on bat myology and osteology (i.e., Macalister, 1872; Vaughan, 1959; Romankowowa, 1961; Walton and Walton, 1970a, 1970b; Vaughan and Bateman, 1970; Norberg, 1972; Cypher, 1996; Panyutina et al., 2015; Reyes-Amaya et al., 2017). Homologies of sesamoids described in different sources were hypothesized primarily using the criterion of topological similarity, i.e., two sesamoids were considered homologs if they were located in the same tendon of the same muscle or in the same ligament. This positional criterion is the conventional means used to infer sesamoid homologies (e.g., Pearson and Davin, 1921a, 1921b; Le Minor, 1987; Vanden Berge and Storer, 1995; Olson, 2000; Hall, 2005; Kawashima et al., 2007; Vickaryous and Olson, 2007; Kim et al., 2009; Jerez et al., 2010; Ponssa et al., 2010; Abdala et al., 2017; and Samuels et al., 2017).

Muscle nomenclature used in this study follows Vaughan (1959). To describe sesamoid locations, the following synonymies of directional terms were applied: (1) medial = preaxial = radial/tibial; (2) lateral $=$ postaxial $=$ ulnar/fibular. These terms were applied to both the forelimb and hind limb to avoid misunderstandings when comparing bat sesamoids to those of other tetrapods. In bats, the hind limbs are rotated $180^{\circ}$ relative to their position in other mammals (Simmons, 1994), so proper terminology is crucial. In the hand (= wing) and foot, the dorsal (extensor) and the palmar (flexor) surfaces are equivalent with those of the limbs of other mammals, so the terms applied are the same. Finally, we applied the term "lunulae" to those sesamoids that, based on their locations, are presumably derived from an ossified meniscus (e.g., Jerez et al., 2010; Samuels et al., 2017).

Sesamoids were examined in the postcranial skeleton of specimens from the following collections: American Museum of Natural History (AMNH), Instituto de Bio y Geociencias del Noroeste Argentino, Salta, Argentina (IBIGEO), Museo Argentino de Ciencias Naturales Bernardino Rivadavia, Buenos Aires, Argentina (MACN-Ma), Royal Ontario Museum (ROM), and Princeton University (now housed at the Yale Peabody Museum; YPM-PU). We examined in detail 10 adult specimens of nine yangochiropteran species representing three extant families: Artibeus planirostris IBIGEO-M 0216, Desmodus rotundus IBIGEO-M 0215, Carollia perspicillata MACN-Ma 14247, and Sturnira lilium MACN-Ma 18350 / IBIGEO-M 0218 (Phyllostomidae); Molossops temminckii MACN-Ma 14151 and Tadarida brasiliensis MACN-Ma 22066 (Molossidae); and Eptesicus furinalis MACN-Ma 49244, Dasypterus ega MACN-Ma 22063, and Myotis levis MACN-Ma 14671 (Vespertilionidae). 

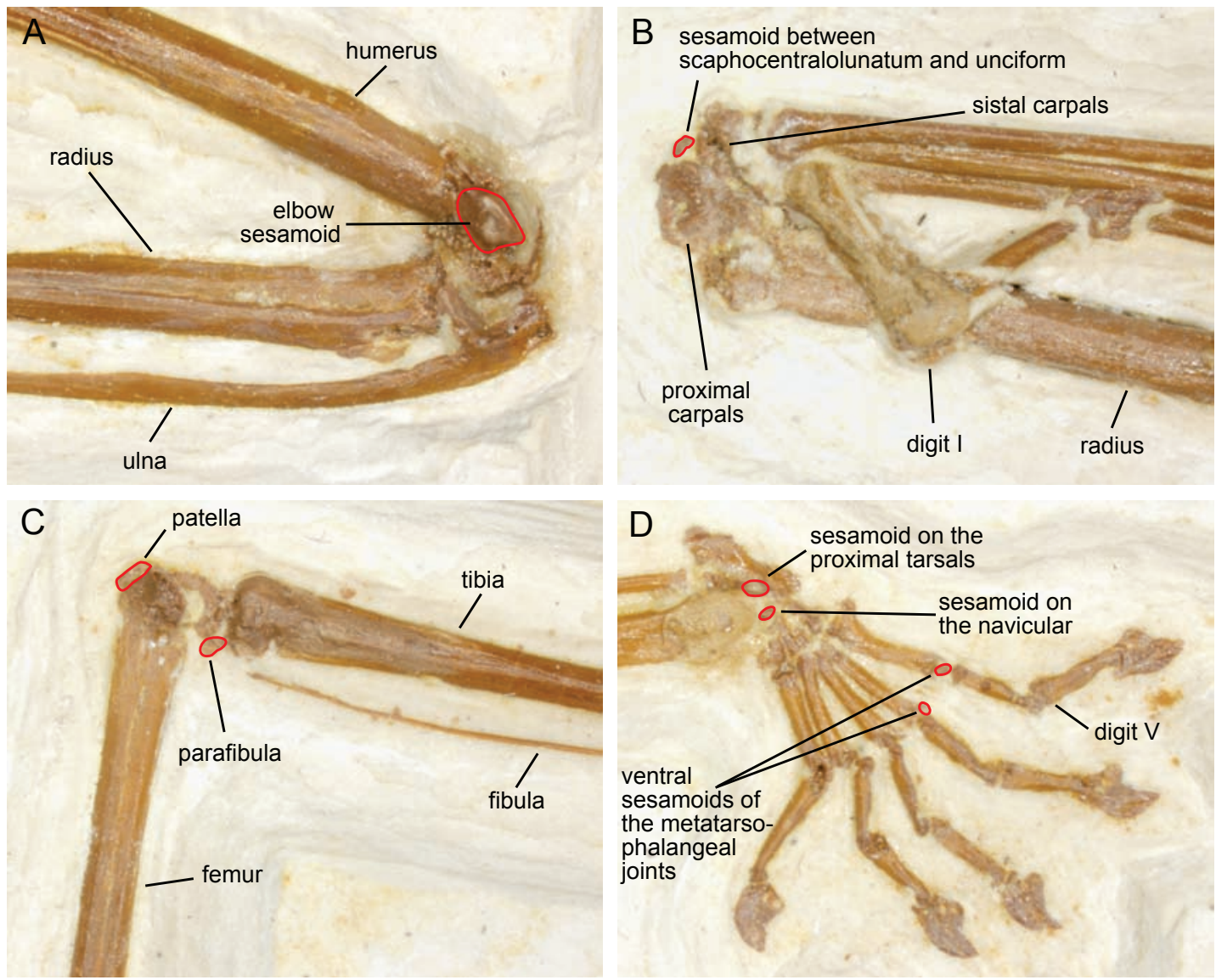

FIG. 1. Eocene bat fossils: Onychonycteris finneyi AMNH 142467 showing some of the preserved sesamoids, highlighted with red lines. A. Left elbow (dorsal view). B. Left carpus (ventral-preaxial). C. Left knee (tibial). D. Right foot (dorsal).

These specimens were cleared and stained following the protocol of Wassersug (1976), and examined under a Leica stereoscopic microscope with an attached camera with which illustrative photographs were taken. We did not attempt to evaluate intraspecific variation in sesamoid complements due to material limitations and the difficulty of clearing, staining, and dissection. With the exception of Sturnira lilium (represented by two individuals found to have identical complements of sesamoids), our samples consisted of one individual only per species. Sesamoid endowment in mammals is known to vary somewhat during ontogeny, with some sesamoids appearing as mineralized structures quite late in adult development (Samuels et al., 2017). This potential source of sesamoid variability was not assessed in our study, although we note that, given the biomechanical demands of flight and the rapid development of adult skeletal morphology in bats, we would not expect much or any variation in sesamoid complements after maturity in bats.

We also examined sesamoids of two fossil taxa, Onychonycteris finneyi ROM55351A, B and AMNH 142467 (Onychonycteridae; Simmons et al., 2008) and Icaronycteris index YPM-PU 18150 (Icaronycteridae; Jepsen, 1966), using high-resolution photographs (figs. 1, 2). Onychonyc- 

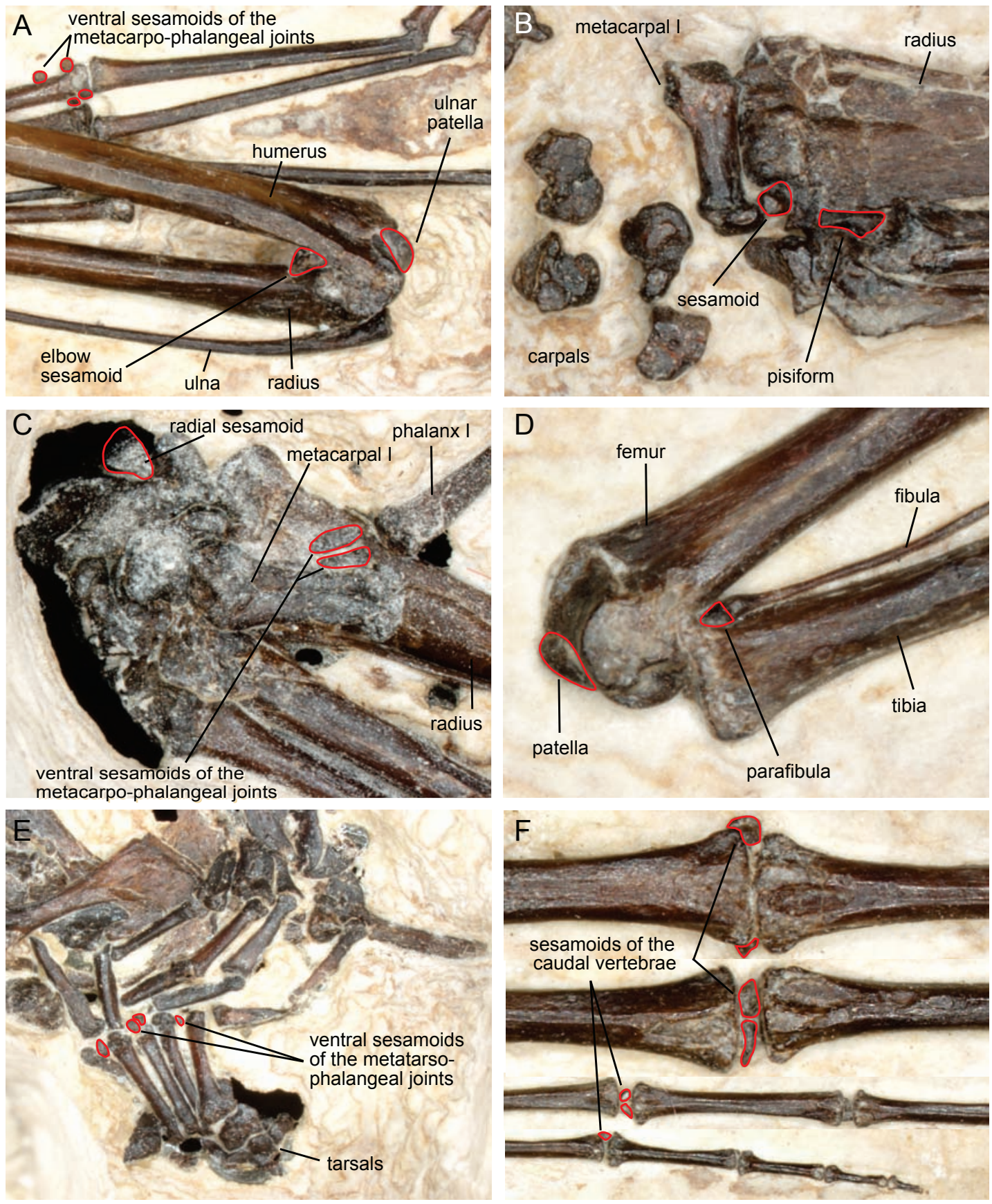

FIG. 2. Eocene bat fossils: Icaronycteris index YPM-PU 18150 showing some of the preserved sesamoids, highlighted with red lines. A. Left elbow (dorsal view). B. Left carpus (dorsal). C. Right tarsus (ventral-preaxial). D. Left knee (fibular). E. Right foot (ventral). F. Sequence of caudal vertebrae (dorsal). 


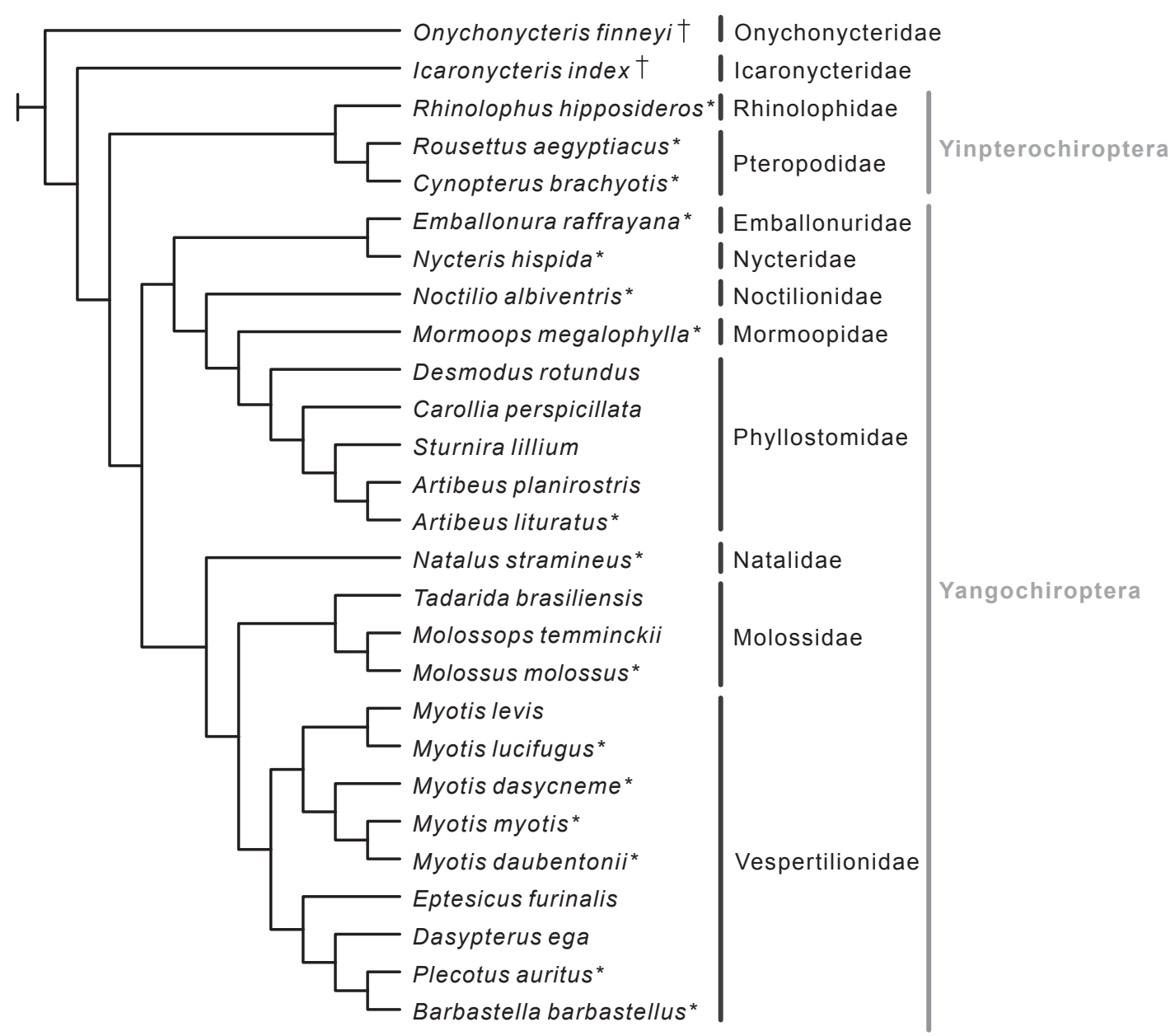

FIG. 3. Phylogeny used in the optimization analysis of sesamoid characters follows relationships proposed by Simmons et al. (2008; extinct taxa indicated with a dagger) and Amador et al. (2018; extant taxa). Species represented in our dataset exclusively by data from autopodial sesamoids compiled from prior studies are indicated with an asterisk $\left(^{*}\right)$.

teris finneyi is Late Wasatchian in age (biochronological zone Wa7; late early Eocene, 52.5 mya) from the Fossil Butte Member of the Green River Formation, Wyoming (Simmons et al., 2008). Icaronycteris index is of similar age from the same formation (see Smith et al., 2012). These fossil taxa represent the successively most basal lineages of Chiroptera (Simmons et al., 2008).

We coded the presence or absence of each sesamoid or set of sesamoids in each of the 11 taxa that we studied. We also compiled literature data on some autopodial sesamoids (i.e., sesamoids associated with joints in the wrist, hand, ankle, or foot) for 16 additional species (fig. 3; Romankowowa, 1961; Norberg, 1972; Cypher, 1996; Reyes-Amaya et al., 2017). These data were combined in a character matrix that included the 46 sesamoid characters listed in table 1 . For ancestral states reconstructions, data from the sesamoid matrix was mapped onto a pruned version of the bat phylogeny of Amador et al. (2018; fig. 3) using parsimony as implemented by the program TNT 
TABLE 1. Bat sesamoid list. Number (no.), general location (FL, forelimb; HL, hind limb; T, tail), specific location, in parentheses (Pc, pectoral girdle; E, elbow; A, manual/pedal autopodium; Pv, pelvic girdle; K, knee), and character description for each sesamoid or set of sesamoids identified in this paper. Character numbers begin with "0" to accommodate phylogenetic analyses in the program TNT (Goloboff et al., 2008).

\begin{tabular}{|c|c|c|}
\hline No. & Location & Character \\
\hline 0 & $\mathrm{FL}(\mathrm{Pc})$ & Sesamoid in ligamentum acromioclaviculare, visible in dorsal view \\
\hline 1 & FL $(\mathrm{E})$ & $\begin{array}{l}\text { Ulnar patella: sesamoid in the insertion of } \mathrm{m} \text {. triceps brachii just proximal to the reduced } \\
\text { olecranon }\end{array}$ \\
\hline 2 & FL $(E)$ & $\begin{array}{l}\text { Sesamoid in the origin of } \mathrm{m} \text {. extensor carpi radialis brevis next to the lateral epicondyle of } \\
\text { humerus }\end{array}$ \\
\hline 3 & FL $(E)$ & $\begin{array}{l}\text { Sesamoid in the origin of m. supinator and } \mathrm{m} \text {. extensor digitorum communis next to the } \\
\text { lateral epicondyle of humerus }\end{array}$ \\
\hline 4 & FL $(\mathrm{E})$ & $\begin{array}{l}\text { Sesamoid in the origin of } \mathrm{m} \text {. flexor carpi ulnaris on the ventral surface of elbow joint } \\
\text { between distal end of humerus and reduced olecranon process of ulna. }\end{array}$ \\
\hline 5 & $\mathrm{FL}(\mathrm{A})$ & Sesamoid embedded in the tendon of $\mathrm{m}$. flexor carpi ulnaris next to its insertion \\
\hline 6 & $\mathrm{FL}(\mathrm{A})$ & $\begin{array}{l}\text { Sesamoid in the insertion of } \mathrm{m} \text {. extensor carpi radialis brevis on the dorsal surface of the } \\
\text { wrist between the magnum and the proximal end of metacarpal III }\end{array}$ \\
\hline 7 & $\mathrm{FL}(\mathrm{A})$ & $\begin{array}{l}\text { Sesamoid near the insertion of } \mathrm{m} \text {. extensor pollicis brevis on the proximal end of the } \\
\text { dorsal surface of metacarpal I }\end{array}$ \\
\hline 8 & FL $(\mathrm{A})$ & Sesamoid on the dorsal surface of wrist between the scaphocentralolunatum and cuneiform \\
\hline 9 & $\mathrm{FL}(\mathrm{A})$ & Sesamoid on the dorsal surface of wrist between the scaphocentralolunatum and unciform \\
\hline 10 & $\mathrm{FL}(\mathrm{A})$ & $\begin{array}{l}\text { Radial sesamoid: sesamoid on the preaxial side of the ventral surface of wrist, origin of } \mathrm{m} \text {. } \\
\text { abductor digiti quinti in pteropodids and some microbats }\end{array}$ \\
\hline 11 & $\mathrm{FL}(\mathrm{A})$ & $\begin{array}{l}\text { Pisiform: sesamoid on the ulnar side of the ventral surface of wrist associated with the } \\
\text { distal row of carpals }\end{array}$ \\
\hline 12 & $\mathrm{FL}(\mathrm{A})$ & $\begin{array}{l}\text { Sesamoid on the ventral surface of wrist between the unciform and the proximal end of } \\
\text { metacarpal V }\end{array}$ \\
\hline 13 & FL (A) & Sesamoid on the ventral surface of wrist on the trapezium \\
\hline 14 & FL (A) & Sesamoid on the ventral surface of wrist between the trapezoid and magnum \\
\hline 15 & FL $(\mathrm{A})$ & $\begin{array}{l}\text { Sesamoid in the insertion of } \mathrm{m} \text {. extensor carpi radialis longus in a medial position between } \\
\text { the scaphocentralolunatum and trapezium }\end{array}$ \\
\hline 16 & $\mathrm{FL}(\mathrm{A})$ & $\begin{array}{l}\text { Dorsal sesamoid on the distal end of metacarpal I adjacent to the metacarpo-pahalangeal } \\
\text { joint }\end{array}$ \\
\hline 17 & $\mathrm{FL}(\mathrm{A})$ & $\begin{array}{l}\text { Dorsal sesamoid on the distal end of metacarpal III or III-V adjacent to the metacarpo- } \\
\text { pahalangeal joint }\end{array}$ \\
\hline 18 & $\mathrm{FL}(\mathrm{A})$ & $\begin{array}{l}\text { Dorsal sesamoid on the distal end of the first phalanx of wing digit I just proximal to the } \\
\text { ungual phalanx }\end{array}$ \\
\hline 19 & FL (A) & Dorsal sesamoid of the distal end of the second phalanx of wing digits III or III-V \\
\hline 20 & $\mathrm{FL}(\mathrm{A})$ & $\begin{array}{l}\text { Medial ventral sesamoid on metacarpo-phalangeal joint } \mathrm{I} \text { in the insertion of } \mathrm{m} \text {. abductor } \\
\text { pollicis brevis }\end{array}$ \\
\hline 21 & $\mathrm{FL}(\mathrm{A})$ & $\begin{array}{l}\text { Lateral ventral sesamoid on metacarpo-phalangeal joint } \mathrm{I} \text { in the insertion of } \mathrm{m} \text {. palmaris } \\
\text { longus and } \mathrm{m} \text {. flexor pollicis brevis }\end{array}$ \\
\hline 22 & FL (A) & Pair of ventral sesamoids (lateral and medial) on metacarpo-phalangeal joints III-V \\
\hline 23 & HL (Pv) & Sesamoid in the origin of m. rectus femoris on the anterodorsal rim of the acetabulum \\
\hline
\end{tabular}


TABLE 1 Continued

\begin{tabular}{|c|c|c|}
\hline 24 & HL $(\mathrm{K})$ & $\begin{array}{l}\text { Suprapatella(e): a single sesamoid or group of } 3 \text { tiny sesamoids on the anterior surface of } \\
\text { the distal end of the femur just proximal to the patella }\end{array}$ \\
\hline 25 & $\mathrm{HL}(\mathrm{K})$ & $\begin{array}{l}\text { Patella: a sesamoid in the insertion tendon of } \mathrm{m} \text {. quadriceps overlaying the patellar groove } \\
\text { of the femur proximal to the cnemial process of tibia }\end{array}$ \\
\hline 26 & HL $(\mathrm{K})$ & $\begin{array}{l}\text { Tibial lunula: wedgelike sesamoid on the anterior surface of the knee joint just distal to the } \\
\text { patella }\end{array}$ \\
\hline 27 & HL $(\mathrm{K})$ & Two small sesamoids (lateral and medial) on the anterior surface of knee joint \\
\hline 28 & HL (K) & One or two lunulae deep inside the knee joint (= ossified meniscus ) \\
\hline 29 & HL (K) & $\begin{array}{l}\text { Parafibula: sesamoid in the insertion of the lateral collateral ligament on the proximal end } \\
\text { of the fibula }\end{array}$ \\
\hline 30 & HL $(\mathrm{K})$ & Fabellae: paired sesamoids in the origin of $\mathrm{m}$. gastrocnemius from the femur epicondyles \\
\hline 31 & $\mathrm{HL}(\mathrm{K})$ & Cyamella: sesamoid in the tendon of $\mathrm{m}$. popliteus near the proximal end of the fibula \\
\hline 32 & HL (A) & Dorsal sesamoid associated to the proximal tarsals near the distal tibia-fibula joint \\
\hline 33 & $\mathrm{HL}(\mathrm{A})$ & Sesamoid in the insertion of the $\mathrm{m}$. tibialis posticus dorsal to the inner cuneiform \\
\hline 34 & HL (A) & Sesamoid dorsal to the navicular \\
\hline 35 & $\mathrm{HL}(\mathrm{A})$ & Sesamoid ventral to the inner cuneiform on the tibial side \\
\hline 36 & HL (A) & Small sesamoid between cuboid and the proximal end of metatarsal V on the ventral side \\
\hline 37 & HL (A) & $\begin{array}{l}\text { One or two small sesamoids (medial and lateral) on the ventral side of the proximal end of } \\
\text { metatarsal V }\end{array}$ \\
\hline 38 & HL (A) & Small sesamoid on the ventral side of the proximal end of metatarsal I \\
\hline 39 & HL (A) & Plantar sesamoid ventral to the middle point of the metatarsal III \\
\hline 40 & HL (A) & Dorsal sesamoid on the metatarso-phalangeal joint of foot digits I-V \\
\hline 41 & HL (A) & Dorsal sesamoid on the first-second phalangeal joint of foot digits I-V \\
\hline 42 & HL (A) & Dorsal sesamoid on the second-third (ungual) phalangeal joint of foot digits II-V \\
\hline 43 & HL (A) & $\begin{array}{l}\text { Sesamoidea phalangis: pair of ventral sesamoids (lateral and medial) on metatarso-phalan- } \\
\text { geal joints } \mathrm{I}-\mathrm{V} \text { in the insertion of } \mathrm{mm} \text {. interossei and of } \mathrm{mm} \text {. adductors and abductors of } \\
\text { digits I and V }\end{array}$ \\
\hline 44 & $\mathrm{~T}$ & $\begin{array}{l}\text { One or two tiny dorsal sesamoids on or near the joints between a variable number of } \\
\text { proximal caudal vertebrae }\end{array}$ \\
\hline 45 & $\mathrm{~T}$ & $\begin{array}{l}\text { One or two tiny ventral sesamoids on or near the joints between a variable number of } \\
\text { proximal caudal vertebrae }\end{array}$ \\
\hline
\end{tabular}

(Goloboff et al., 2008). We treated the two fossil taxa in our study, Onychonycteris finneyi and Icaronycteris index, as consecutive outgroups to the chiropteran crown group following Simmons et al. (2008). Sesamoids not observed in the two extinct taxa were coded as "missing" ("?") instead of "absent" because we could not be sure whether they were truly absent in an evolutionary sense or simply missing due to preservation effects. The only sesamoid characters scored as "inapplicable" (coded as "-") were characters 44 and 45 in the case of the phyllostomids Desmodus rotundus, Artibeus planirostris, and Sturnira lilium. These characters describe the sesamoids related to the caudal vertebrae, and the above-mentioned species all have a reduced or absent tail. 

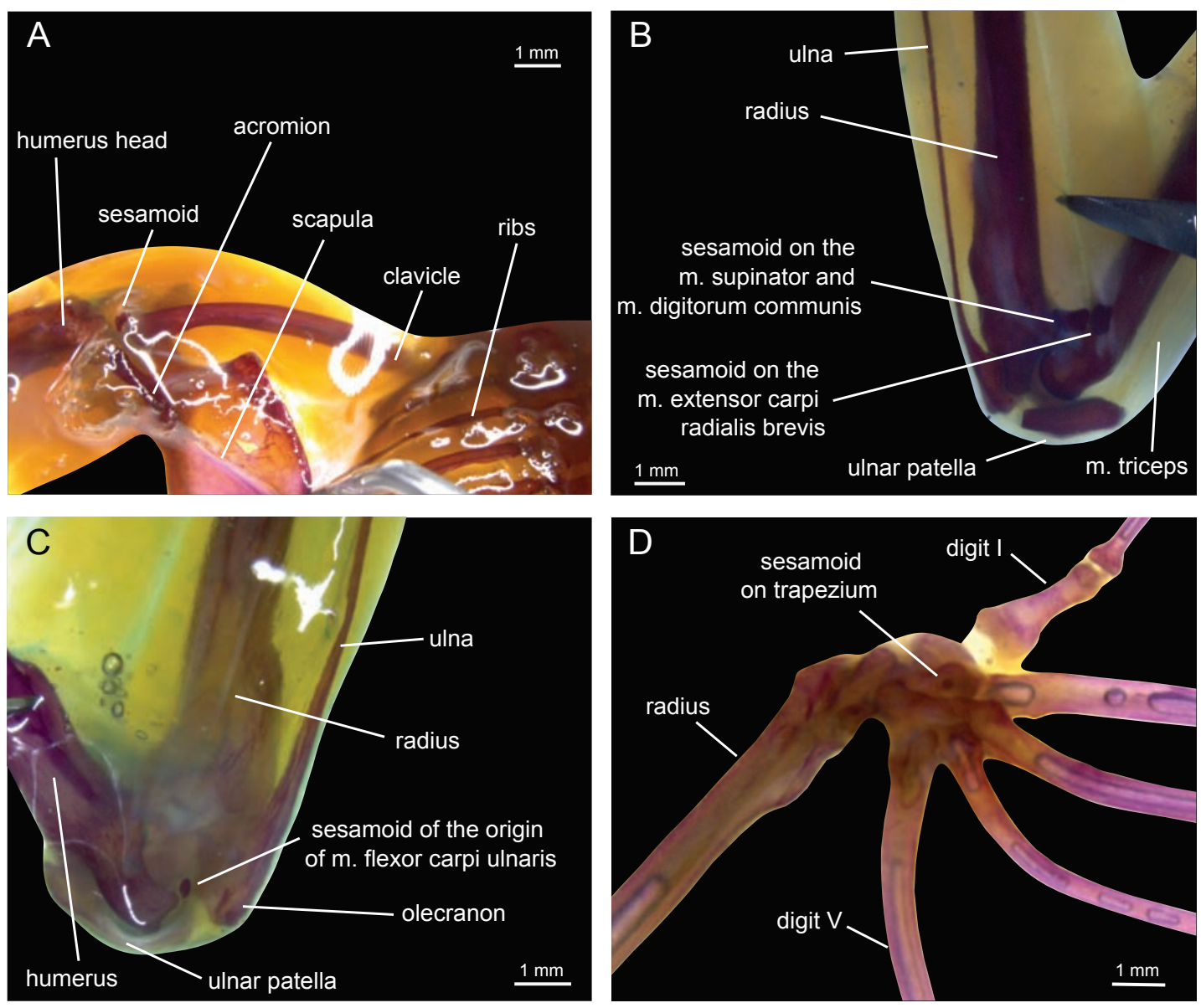

FIG. 4. Selected sesamoids in the forelimb of various extant species. A. Left shoulder of Dasypterus ega (dorsal view). B. Left elbow of Molossops temminkii (dorsal). C. Left elbow of Tadarida brasiliensis (ventral). D. Right carpus of Eptesicus furinalis (dorsal).

\section{RESULTS}

A list of the sesamoids observed in bats, including anatomical position and names (when available), is provided in table 1 . In our dissections we observed a total of 46 bat sesamoids or sesamoid series, including 23 in the forelimb (one related to the shoulder joint, four related to the elbow joint, and the remainder related to the autopodial joints; figs. 4, 5), 21 sesamoids in the hind limb (one related to the hip joint, eight to the knee joint, and the remainder to the autopodial joints; figs. 6,7), and two sesamoid series whose representation is spread across proximal tail vertebrae (fig. 7). Of the 44 sesamoid characters described herein for the limbs, 25 occur in association with extensor muscles and/or extensor surfaces of joints, while the remaining 19 occur in association with flexor muscles and/or surfaces.

A comparison between the sesamoids that we identified and those reported in prior studies is shown in table 2. Most of the sesamoids that we found have been reported at least once in 

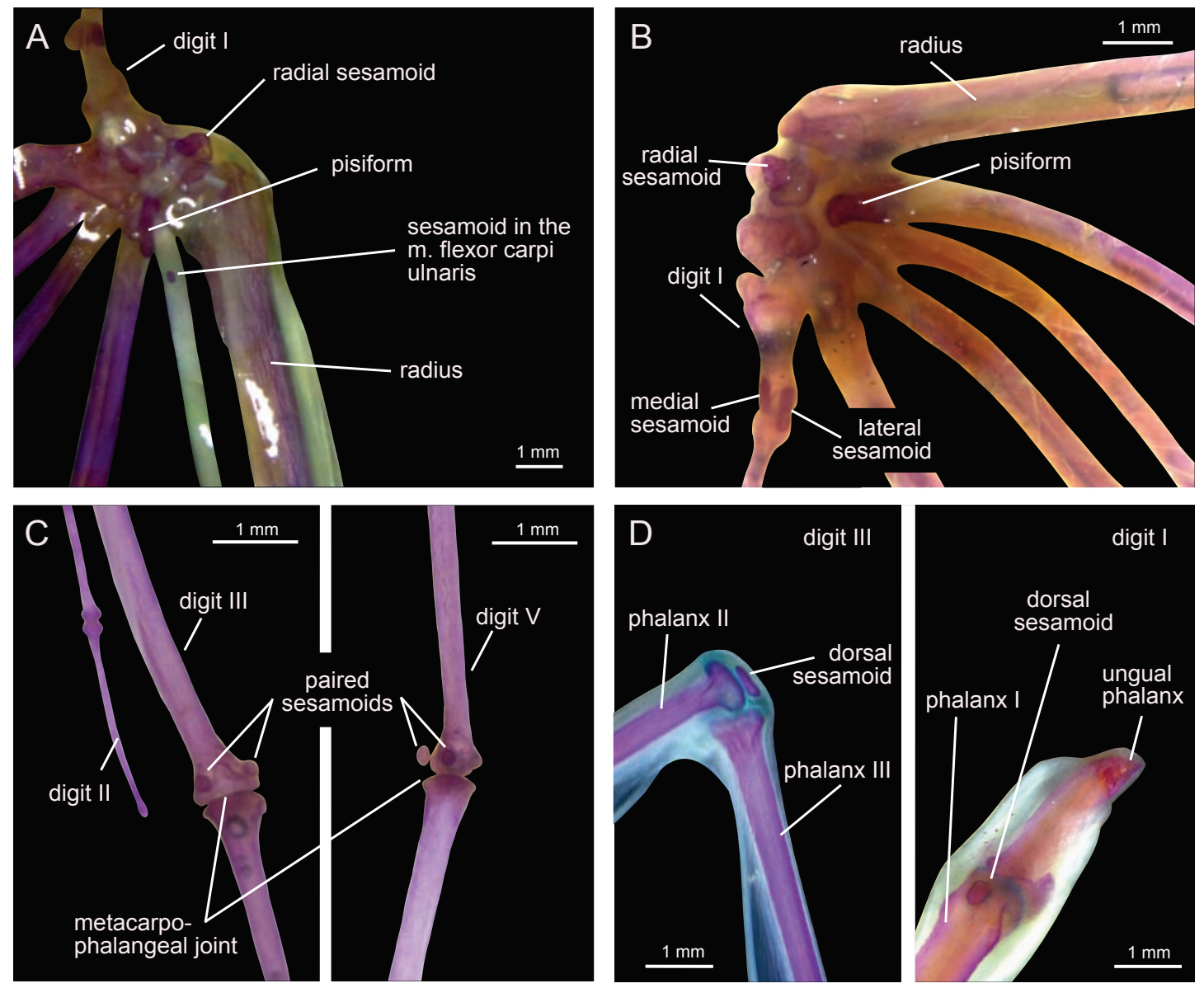

FIG. 5. Selected sesamoids in the forelimb of various extant species. A. Right carpus of Tadarida brasiliensis (ventral). B. Right carpus of Eptesicus furinalis (ventral). C. Metacarpo-phalangeal joint of wing digits II, III, and $\mathrm{V}$ of E. furinalis (ventral). D. Interphalangeal joints of wing digits III (lateral) and I (dorsolateral) of Artibeus planirostris.

previous studies, although often only in passing discussions of other structures (e.g., muscles). However, we found 12 sesamoids not described previously in bats. These include a sesamoid on the dorsal surface of wrist between the scaphocentralolunatum and the unciform (char. 9; fig. 1); a sesamoid on the ventral surface of wrist on the trapezium (char. 13); a dorsal sesamoid on the distal end of second phalanx of wing digits III or III-V (char. 19; fig. 5); the suprapatella (described by Smith et al., 1995, but not referred to as a sesamoid structure; char. 24; fig. 6); the tibial lunula (char. 26; fig. 6); two small sesamoids (lateral and medial) on the anterior surface of knee joint (char. 27); the lunulae (one or two) inside the knee joint (char. 28; fig. 6); the fabellae (char. 30); the cyamella (char. 31); a small ventral sesamoid on the proximal end of metatarsal I (char. 38); and sesamoids associated with the caudal vertebrae (chars. 44 and 45; figs. 1, 7). Table 3 summarizes seven sesamoids mentioned in the literature on bats that were absent in the taxa in our sample. All these sesamoids are autopodial, with four found in 

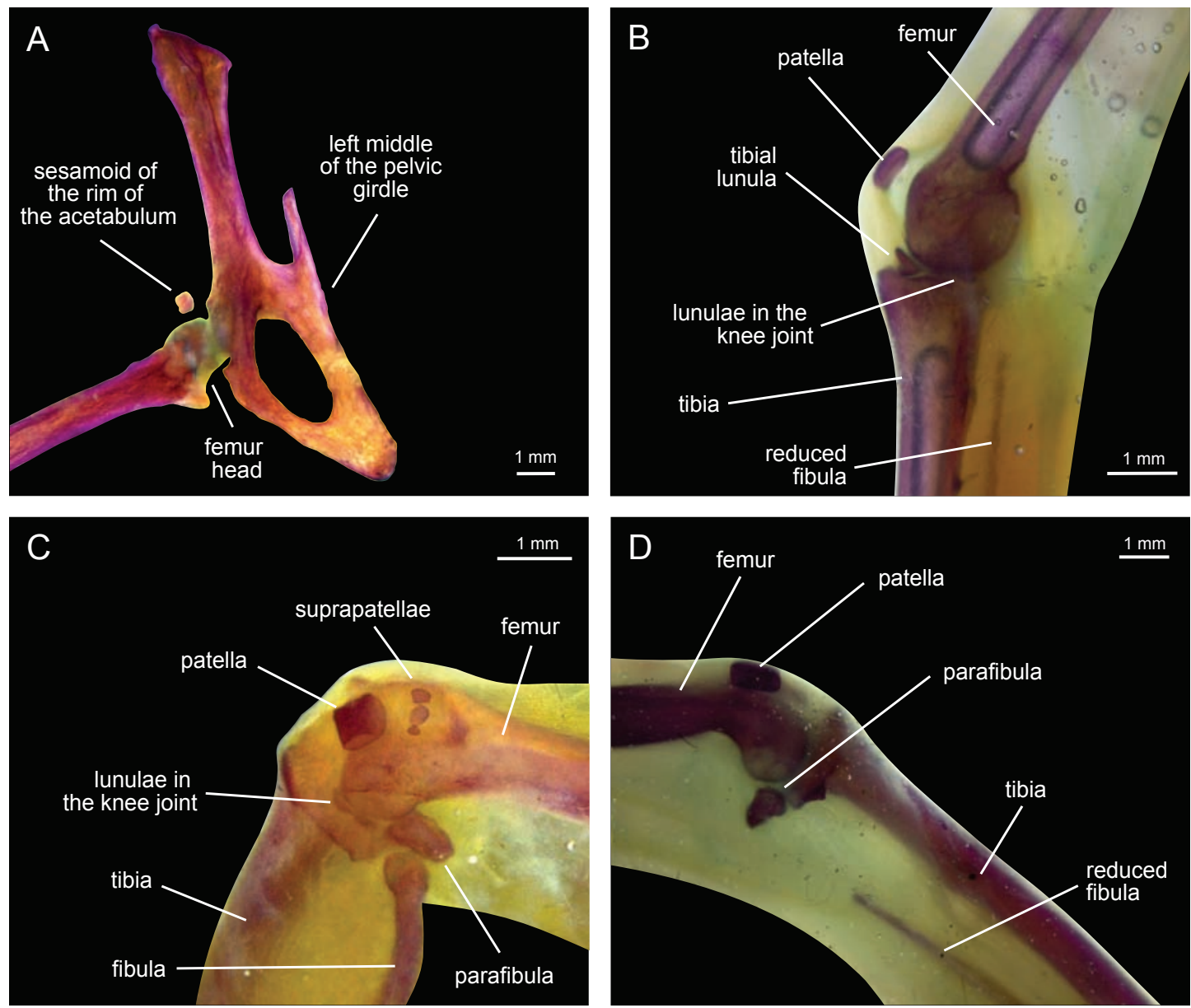

FIG. 6. Selected sesamoids in the hind limb and tail of various extant species. A. Left joint between pelvic girdle and femur of Carollia perspicillata (dorsal view). B. Right knee of Eptesicus furinalis (tibial). C. Left knee of Tadarida brasiliensis (fibular). D. Left knee of Sturnira lilium (tibial).

the handwing and three in the foot. Among the extant species examined in our study, those exhibiting the greatest number of sesamoids were Tadarida brasiliensis and Molossops temminckii (23 and 22 sesamoids or sets of sesamoids), both members of the family Molossidae. Desmodus rotundus and Sturnira lillium (Phyllostomidae) each had 20 sesamoids, and the rest of the species in our study exhibited 15-18 sesamoids or sets of sesamoids (table 4).

Preservation of a large number of minute sesamoid elements in small Eocene bat specimens is truly remarkable. In his description of Icaronycteris, Jepsen (1966) reported a total of 44 individual sesamoid elements (many of these representing homologs preserved on both sides of the skeleton); of these he named and figured just two, the pisiform and a "sesamoid of right wrist," which we identified as the radial sesamoid (our char. 10). We positively identified 10 and 12 sesamoids (or sets of sesamoids) in Onychonycteris and Icaronycteris, respectively (table 4). Five of these, the medial ventral sesamoid on the metacarpo-phalangeal joint I (char. 20), the lateral ventral sesamoid on the metacarpo-phalangeal joint I (char. 21), the 

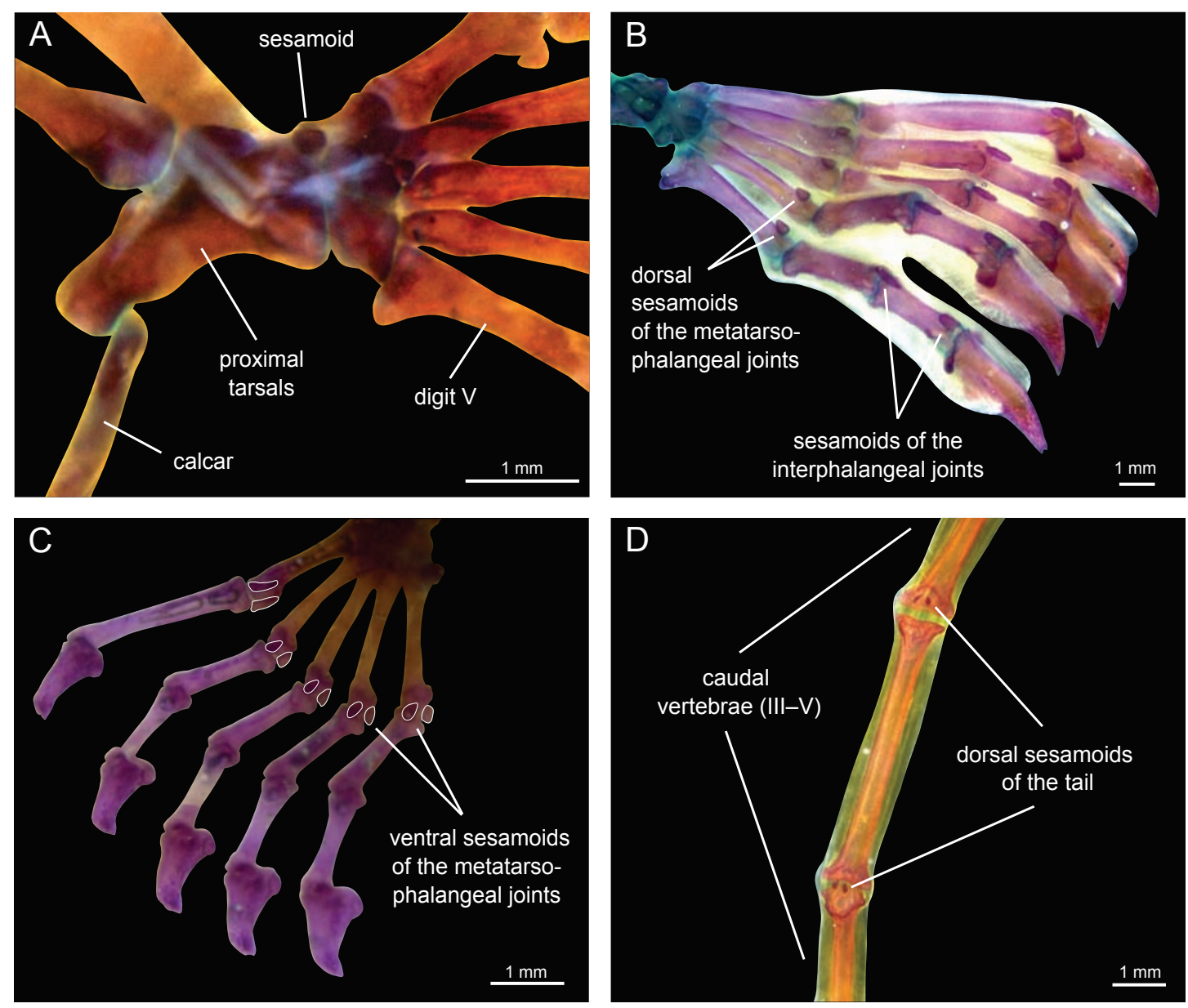

FIG. 7. Selected sesamoids in the hind limb and tail of various extant species. A. Right tarsus of Dasypterus ega (dorsal). B. Right autopodium of Artibeus planirostris (dorsal). C. Right autopodium of Eptesicus furinalis (ventral). D. Caudal vertebrae of E. furinalis (dorsal).

femoral patella (char. 25), the parafibula (char. 29), and the pedal ossa sesamoidea phalangis (char. 43) were identified in both taxa (table 4). None of the sesamoids were exclusively present in the fossil taxa.

Mapping analyses of the sesamoid dataset (table 4) onto the phylogeny revealed that 34 of the 46 sesamoid characters showed potentially significant evolutionary patterns. Seven sesamoid characters (chars. 13, 18, 19, 24, 26, 39, and 40; fig. 8) were associated with particular chiropteran clades (table 5), hence their presence may represent synapomorphies of the clades in question. However, analyses of a wider taxonomic sample will be necessary to test these observed patterns. Seven sesamoid characters (chars. 10, 11, 20, 21, 22, 25, and 43; fig. 9) were found to be present in all terminal taxa that could be scored, suggesting that they are plesiomorphic for crown Chiroptera. Seven other sesamoid characters (chars. 0, 14, 27, 30, 31, 33, and 38; fig. 10) were found to occur only in one sampled taxon each; these may represent autapomorphies, though, again, greater taxonomic sampling are necessary to test these hypoth- 


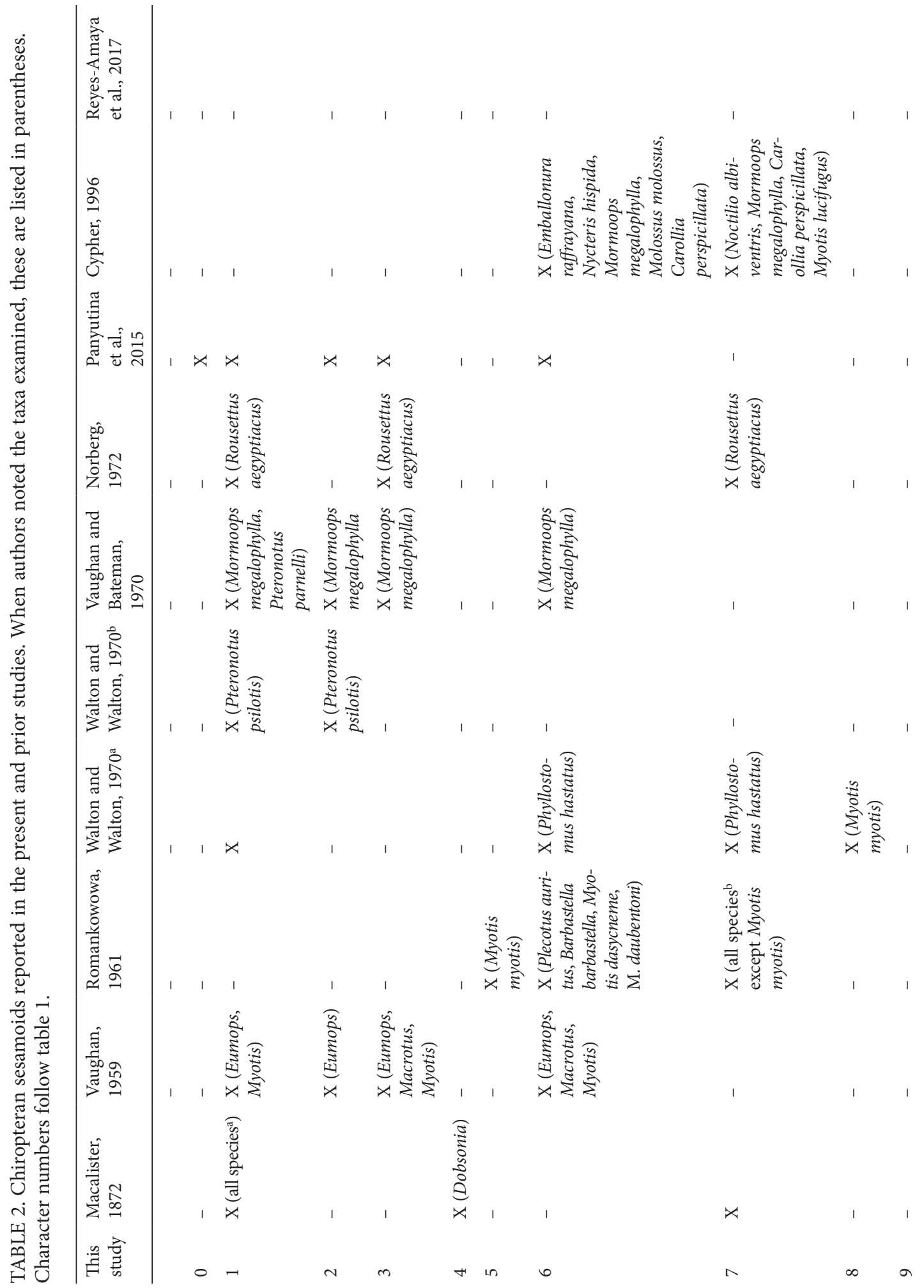




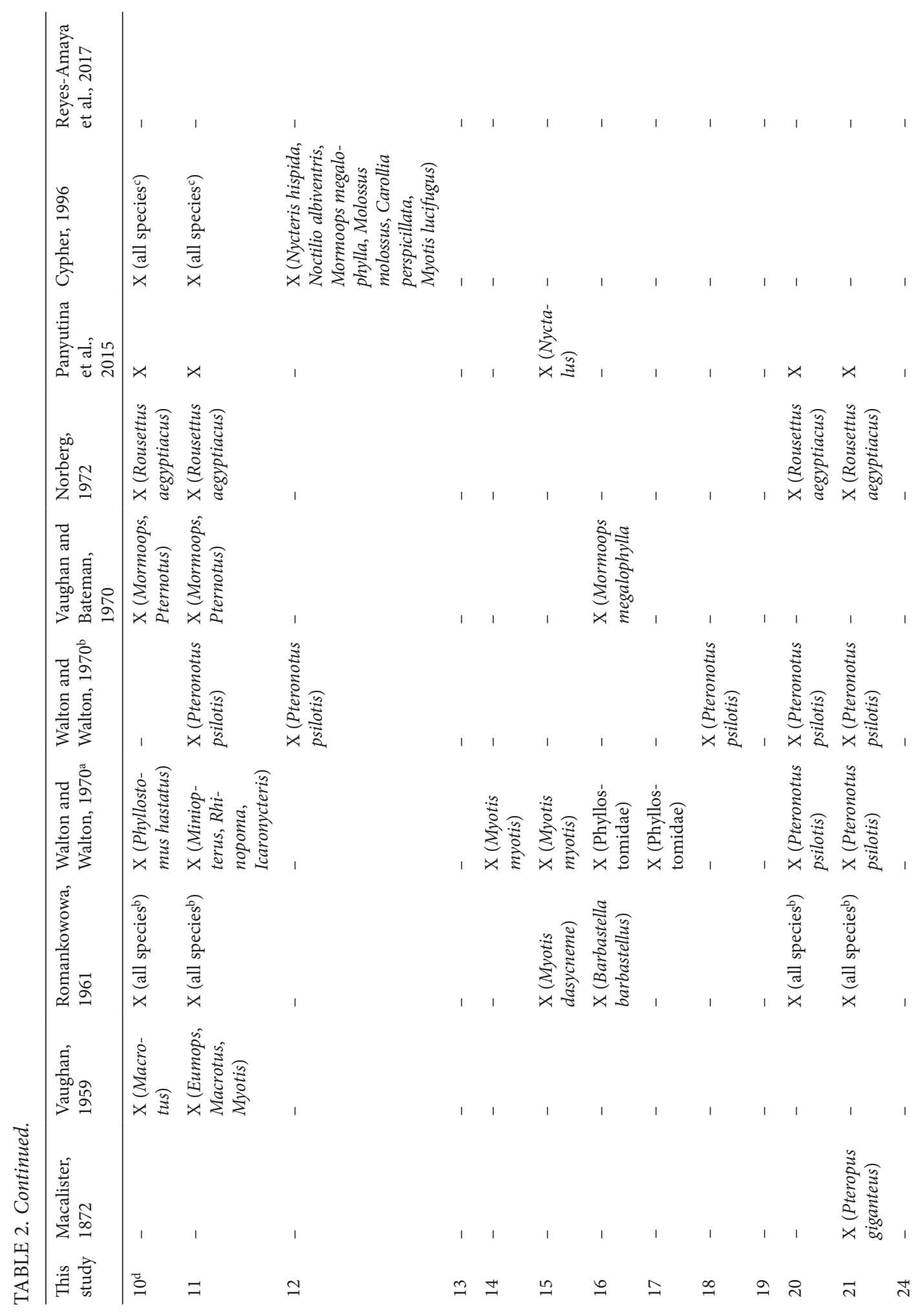




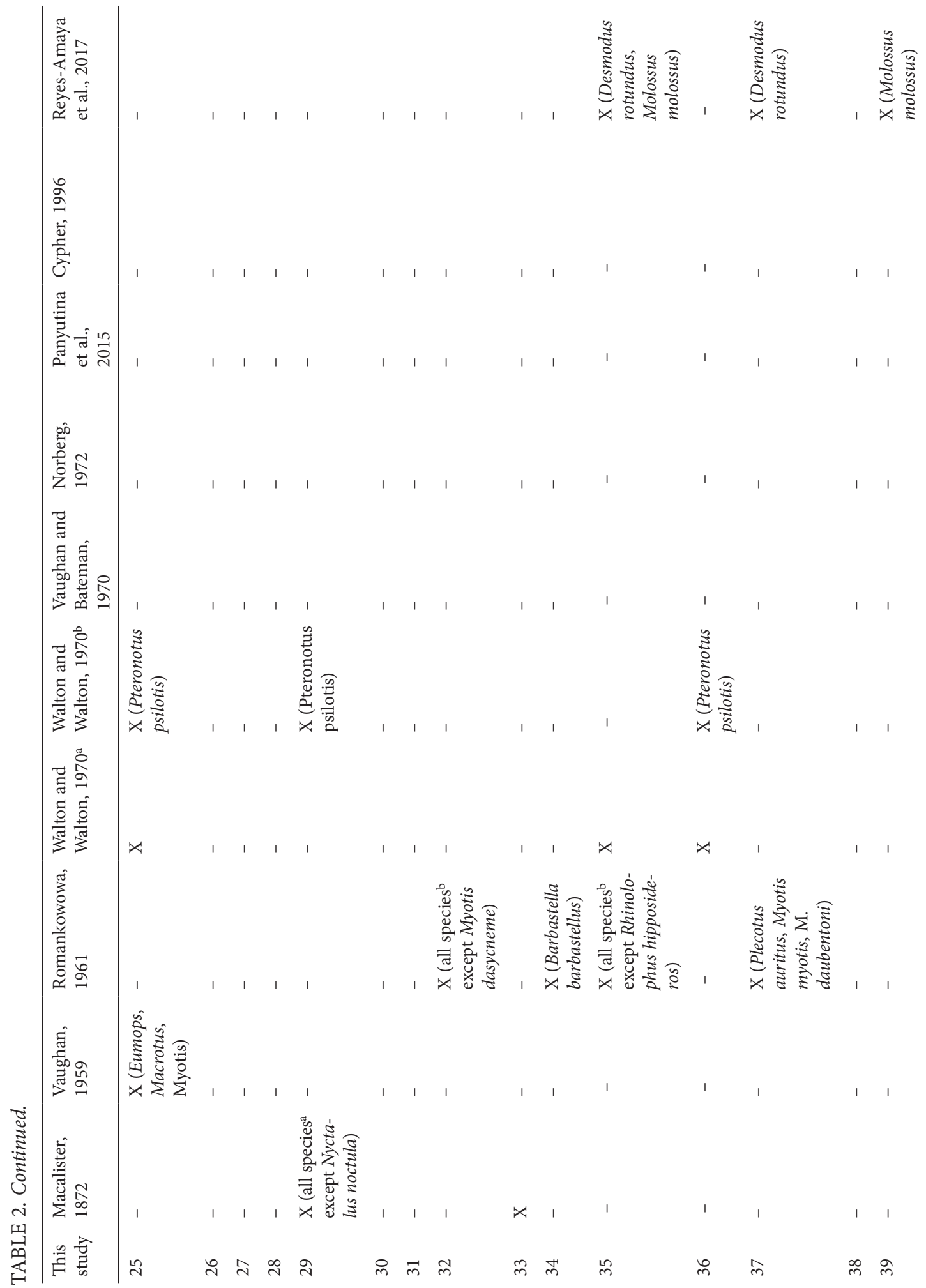




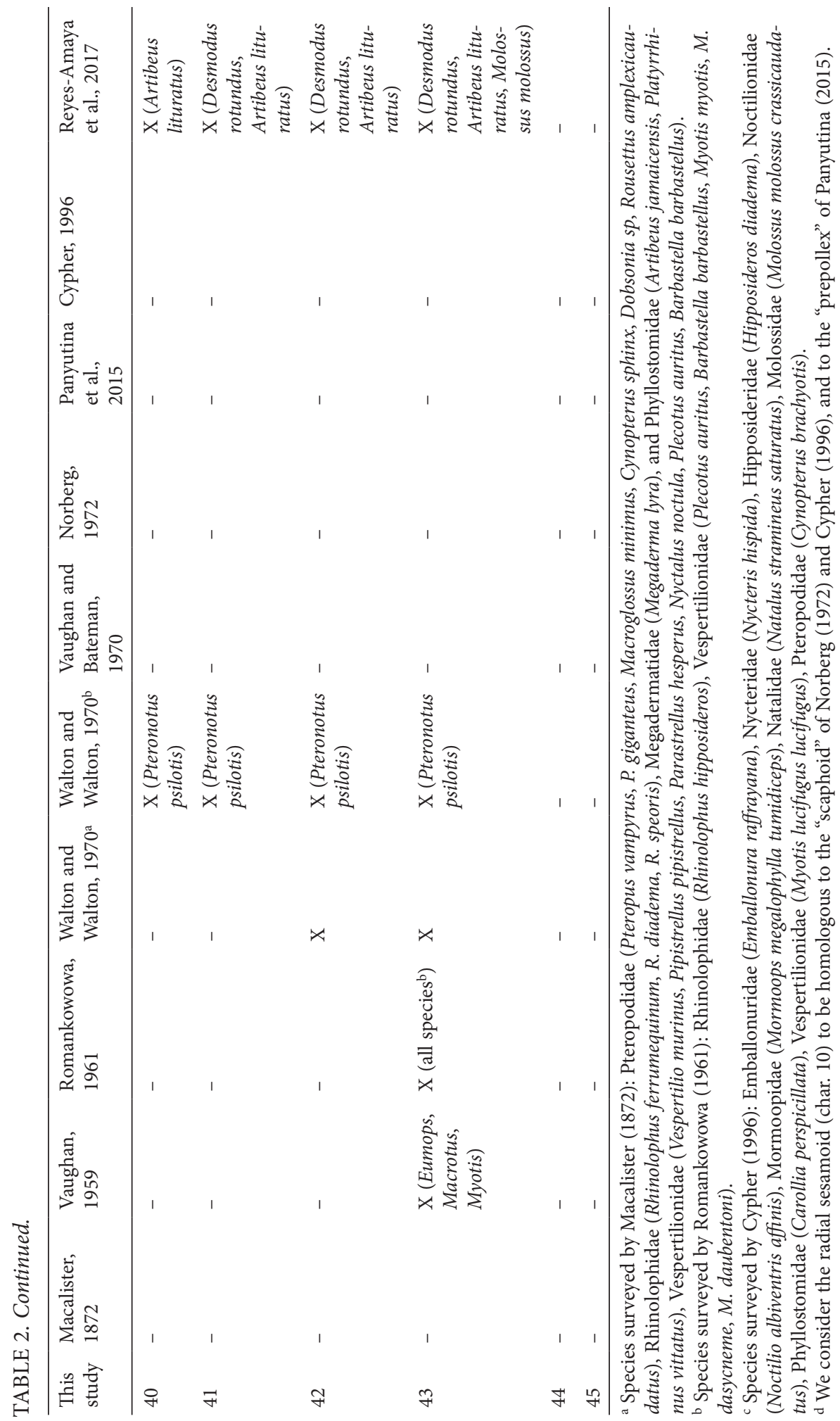


TABLE 3. Sesamoids described in prior studies of bats that were not present in any of the species in our sample. The taxa in which each sesamoid was observed are indicated in parentheses.

\begin{tabular}{|c|c|c|c|c|c|}
\hline & Character & $\begin{array}{l}\text { Vaughan, } \\
1959\end{array}$ & $\begin{array}{l}\text { Walton and Walton, } \\
\text { 1970a }\end{array}$ & Cypher, 1996 & $\begin{array}{l}\text { Reyes-Amaya } \\
\text { et al., } 2017\end{array}$ \\
\hline I & $\begin{array}{l}\text { Sesamoid of the ventral } 4 \text { th } \mathrm{m} \text {. } \\
\text { interossei (origin, on the base of } \\
\text { metacarpal IV) }\end{array}$ & $\begin{array}{l}\mathrm{X} \\
\text { (Eumops, } \\
\text { Macrotus, } \\
\text { Myotis) }\end{array}$ & - & - & - \\
\hline II & $\begin{array}{l}\text { Sesamoid on the metacarpo-phalan- } \\
\text { geal joint II (ventral) }\end{array}$ & - & $\mathrm{X}$ (Pteronotus psilotis) & - & - \\
\hline III & $\begin{array}{l}\text { Sesamoid dorsal to scaphocentralol- } \\
\text { unatum-radius articulation }\end{array}$ & - & - & $\begin{array}{l}\mathrm{X}(\text { Hipposideros } \\
\text { diadema, Noctilio } \\
\text { albiventris })\end{array}$ & - \\
\hline IV & $\begin{array}{l}\text { Sesamoid dorsal to unciform-mag- } \\
\text { num articulation }\end{array}$ & - & - & $\begin{array}{l}\mathrm{X} \text { (Noctilio albiven- } \\
\text { tris, Mormoops meg- } \\
\text { alophylla, Natalus } \\
\text { stramineus, } \\
\text { Myotis lucifugus) }\end{array}$ & - \\
\hline $\mathrm{V}$ & $\begin{array}{l}\text { Tibial ventral sesamoid (on the } \\
\text { distal epiphysis) }\end{array}$ & - & - & - & $\begin{array}{l}\mathrm{X} \text { (Artibeus } \\
\text { lituratus) }\end{array}$ \\
\hline VI & $\begin{array}{l}\text { Calcaneus dorsal sesamoid (on the } \\
\text { distal tip) }\end{array}$ & - & - & - & $\begin{array}{l}\mathrm{X} \text { (Molossus } \\
\text { molossus) }\end{array}$ \\
\hline VII & $\begin{array}{l}\text { Astragalus ventral sesamoid (on the } \\
\text { proximal tip) }\end{array}$ & - & - & - & $\begin{array}{l}\mathrm{X}(\text { Artibeus } \\
\text { lituratus })\end{array}$ \\
\hline
\end{tabular}

eses. Eight characters were reconstructed as independent acquisitions (chars. 5, 8, 9, 16, 34, 35, 36 , and 41), with four of them (chars. 8, 9, 34, and 36; fig. 11) occurring in one of the two fossil taxa. Finally, five sesamoids were apparently independently lost in different chiropteran lineages (chars. 1-3, 6, and 32; fig. 12).

\section{DISCUSSION}

Our survey of sesamoids in Chiroptera indicates that there are roughly similar numbers of sesamoids in the forelimb versus the hind limb, with 23 vs. 21 sesamoids, respectively. In the forelimb, a majority of the sesamoids are located in the autopodium (18, or 78\%, in the wrist/ hand), while in the hind limb sesamoids are more evenly distributed across joints (only 12, or $57 \%$, in the ankle/foot). In the bat forelimb, muscle bellies are concentrated proximally and they transition more distally into elongated tendons that are associated with multiple supporter and glide sesamoids. The development of this conspicuous tendinous system toward the distal wing may be related to the aerodynamic importance of reducing weight near the tip of the wing (in order to reduce inertial power) since gracile tendons weigh considerably less than heavy muscles (e.g., Norberg, 1990). Fast-running tetrapods, such as felids and horses, also exhibit a trend to develop proximally concentrated muscle bodies that transmit their kinetic forces down through long tendons (Alexander, 1984; Hudson et al., 2011a, 2011b; Cuff et al., 2016). It has been suggested that considerable energy can be stored as elastic strain in these long tendons 


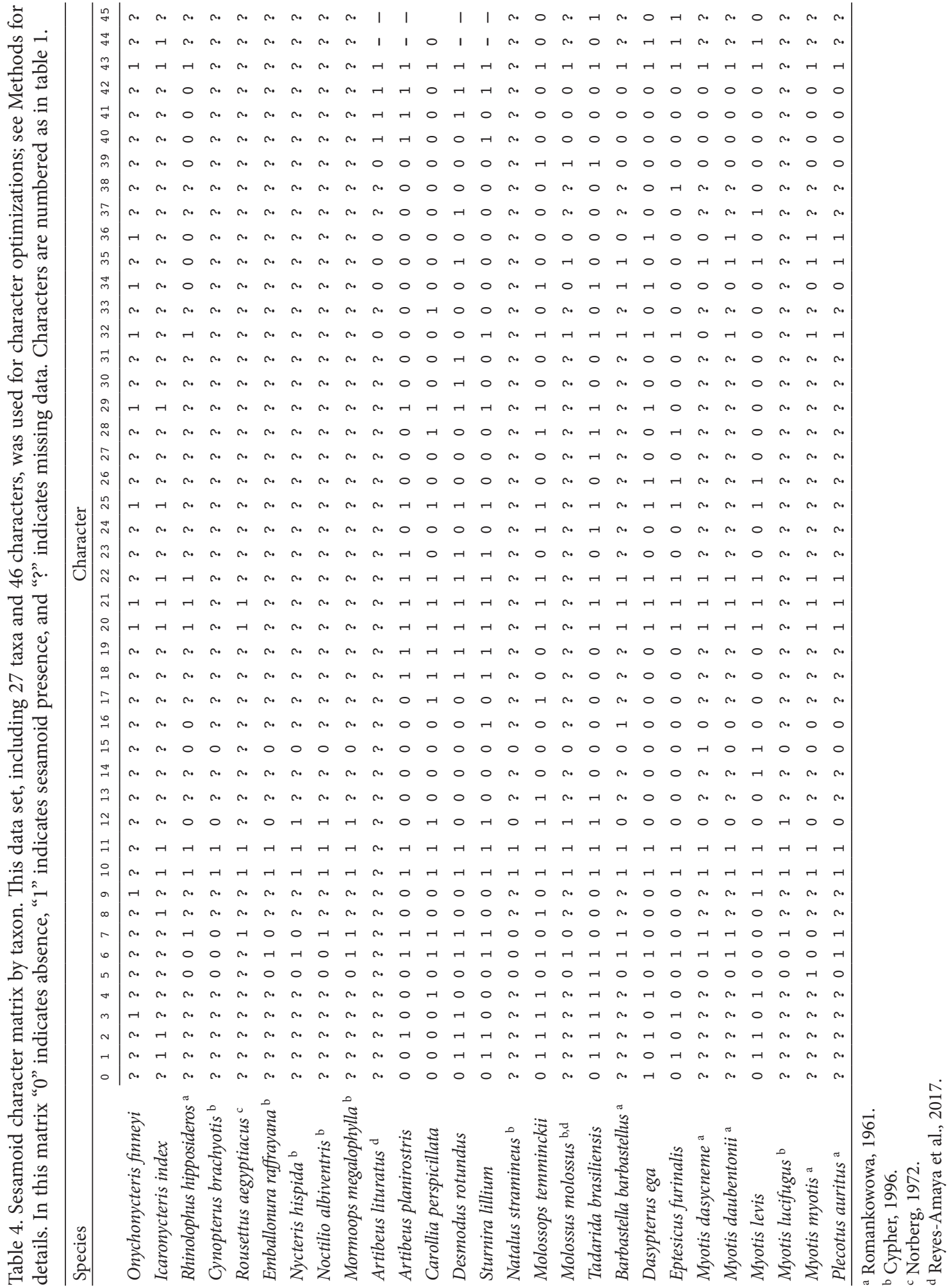


TABLE 5. Sesamoid characters apparently present in particular chiropteran clades; see discussion in text. Characters are numbered as in table 1.

\begin{tabular}{|c|c|}
\hline Clade & Character \\
\hline \multirow[t]{2}{*}{ Phyllostomidae } & $\begin{array}{l}\text { 18: Dorsal sesamoid on the distal end of the first phalanx of wing digit I just proximal to the } \\
\text { ungual phalanx }\end{array}$ \\
\hline & 19: Dorsal sesamoid of the distal end of the second phalanx of wing digits III or III-V \\
\hline Stenodermatinae & 40: Dorsal sesamoid on the metatarso-phalangeal joint of foot digits I-V \\
\hline \multirow[t]{3}{*}{ Molossidae } & 13: Sesamoid on the ventral surface of wrist on the trapezium \\
\hline & 24: Suprapatella(e) \\
\hline & 39: Plantar sesamoid ventral to the middle point of the metatarsal III \\
\hline Vespertilionidae & 26: Tibial lunula \\
\hline
\end{tabular}

(Cuff et al., 2016), and the same function may apply to the long tendons in bat wings (e.g., Konow et al., 2015). Regardless, the evolution of the expanded tendinous system in the handwing of bats may have been facilitated by the acquisition of sesamoids to aid in the functional organization of the elongated tendons, acting to help avoid bowstringing and/or tendon slippage around joints during the wingbeat cycle. Differences in the relative distribution of sesamoids within the bat forelimb and hind limb may thus be at least partially explained by the specializations of the forelimb for flight.

In the present study, we identified 46 sesamoid characters that correspond to 89 individual elements if all were present in a hypothetical bat (counting one side of the body for limb characters). This is a higher number than any previously identified for any vertebrate; anurans, for example, exhibit variation in 20 sesamoid characters corresponding to 54 individual elements (maximum hypothetical number; Ponssa et al., 2010), while lizards show variation in 41 characters, corresponding to 67 individual elements (maximum hypothetical number; Jerez et al., 2010). This preliminary comparison, based on an admittedly small sample of bats, illustrates the remarkable complement of sesamoids variously found in Chiroptera; future studies including a broader taxonomic sample will likely increase these numbers. Individual bat species also apparently have a large number of sesamoids if we compare the sesamoid endowment of the bat species with the highest number of sesamoid characters scored positively, Tadarida brasiliensis with 23 sesamoids (or sets of sesamoids), with the 14 described for dogs (Canis lupus familiaris; Evans and De Lahunta, 2013) and the six sesamoids frequently present in humans (Homo sapiens; Bizarro, 1921).

\section{Evolution, Function, and Development of Selected Sesamoids}

Ulnar PATELla. The ulnar patella (char. 1) is a large sesamoid associated with the insertion of the tendon of $\mathrm{m}$. triceps. An ulnar patella is present among tetrapods in several groups including anurans (Vickaryous and Olson, 2007; Ponssa et al., 2010), lizards (Jerez et al., 2010), and birds (Barnet and Lewis, 1958; Vickaryous and Olson, 2007). Among mammals, the ulnar patella has been found only in bats (Gunn, 1928; Haines, 1940; Walton and Walton, 1970a) with an 

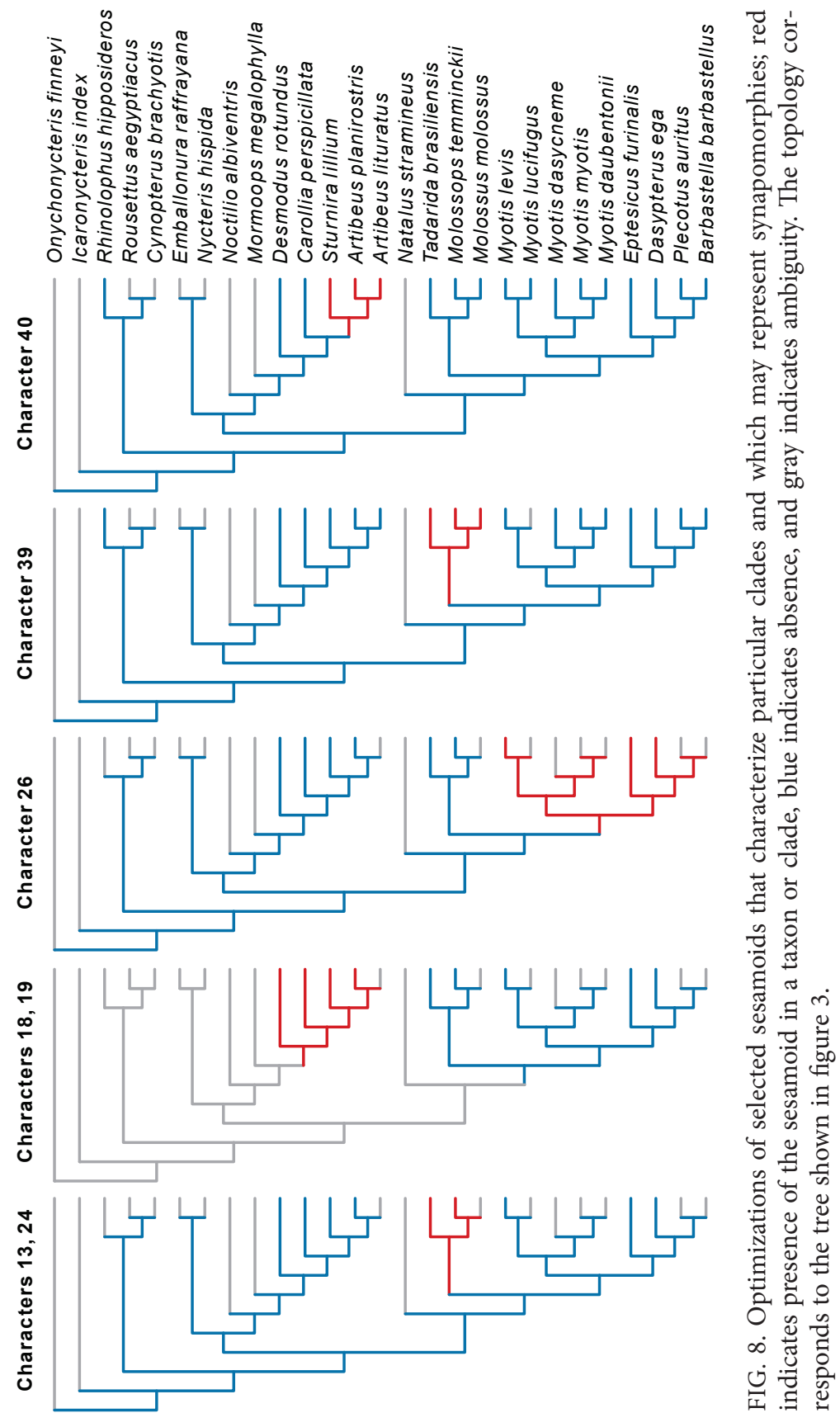

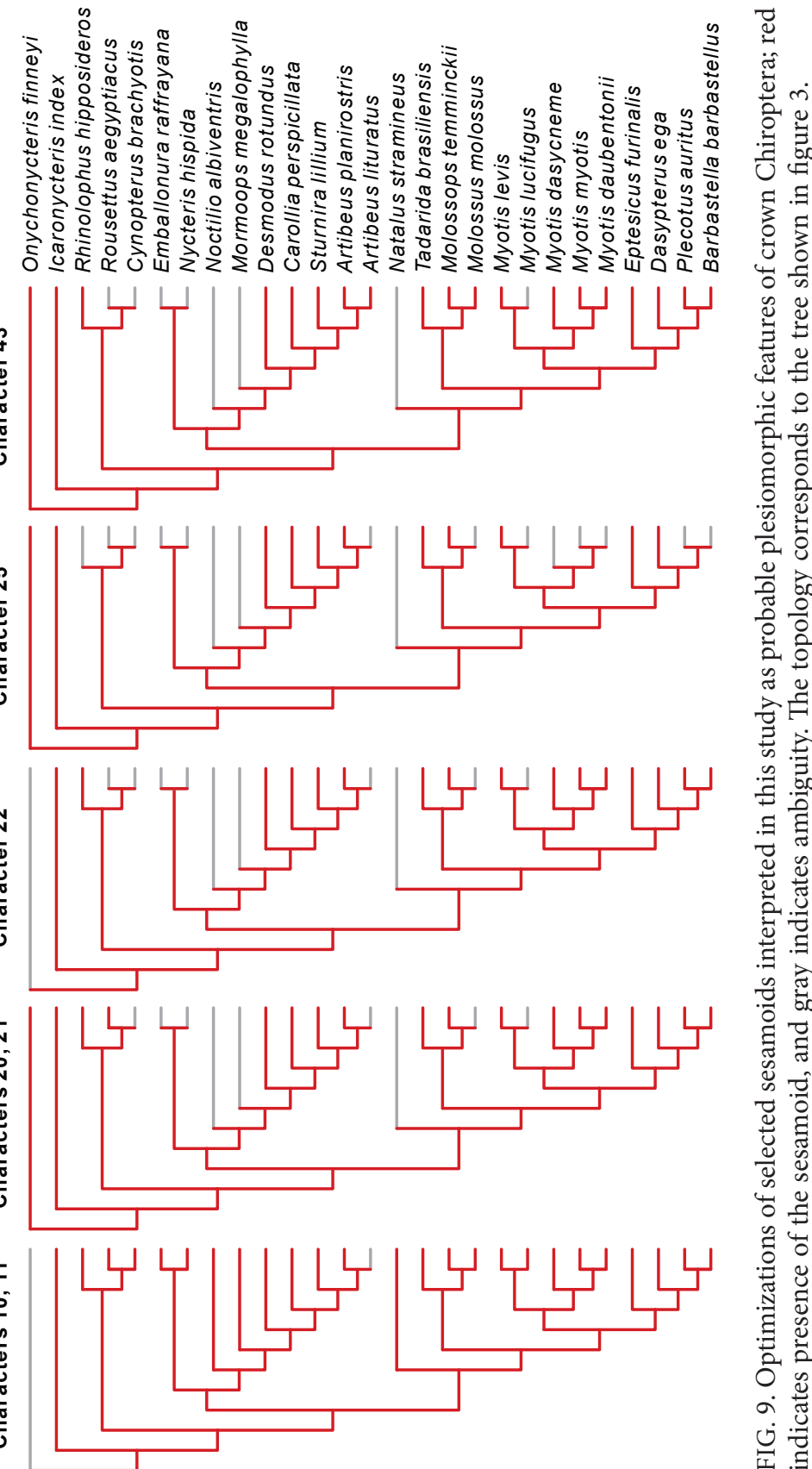

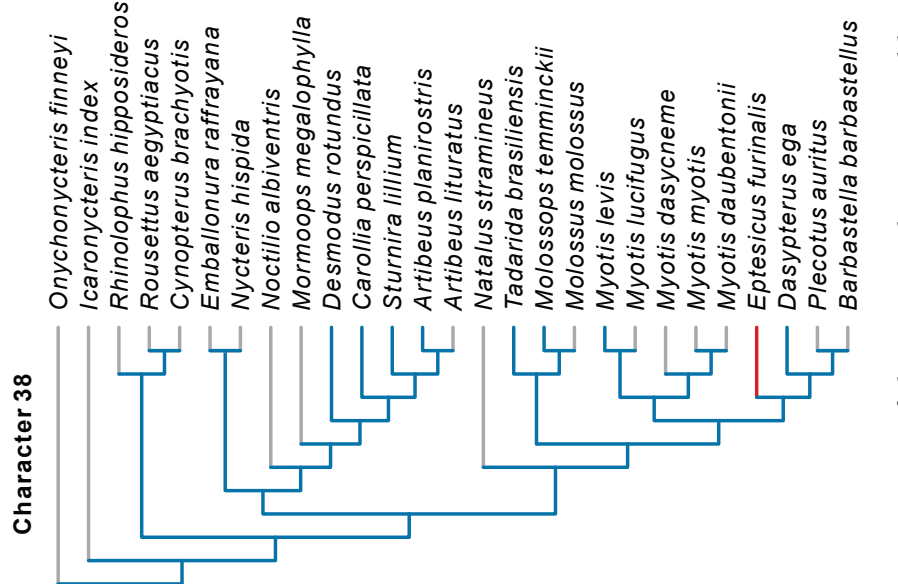

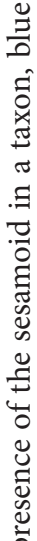

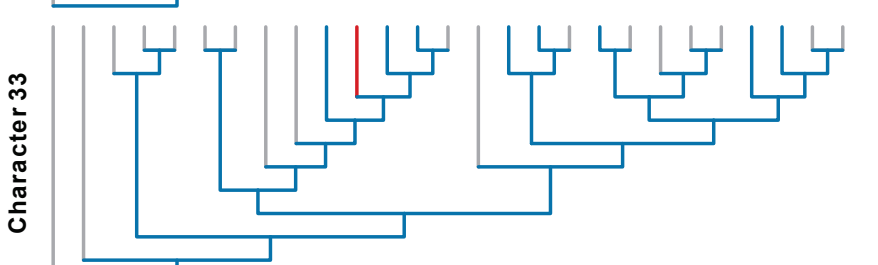

$\underbrace{2}$

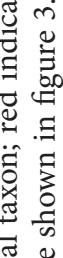

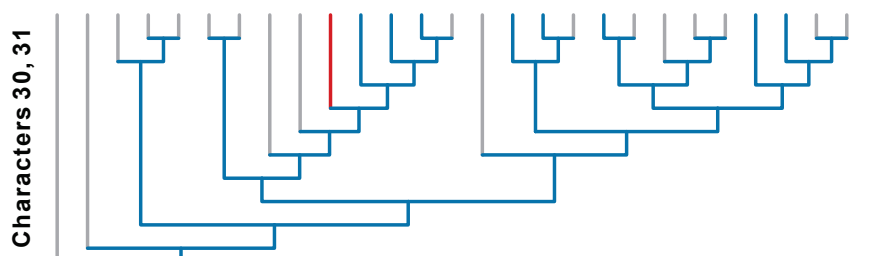

远 오

㒸 $\exists$ 范

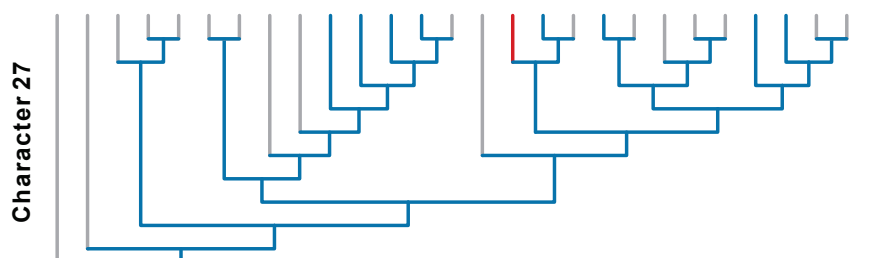

党命

年

$+$

言

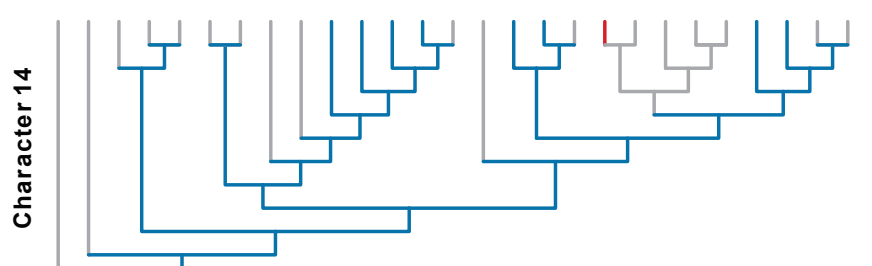

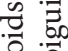

हี त्ञ

$\infty$

过

$\stackrel{ \pm}{*}$.

Ч त्ञ

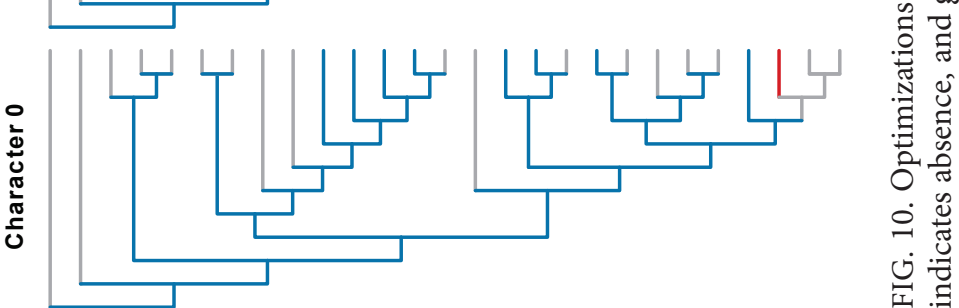




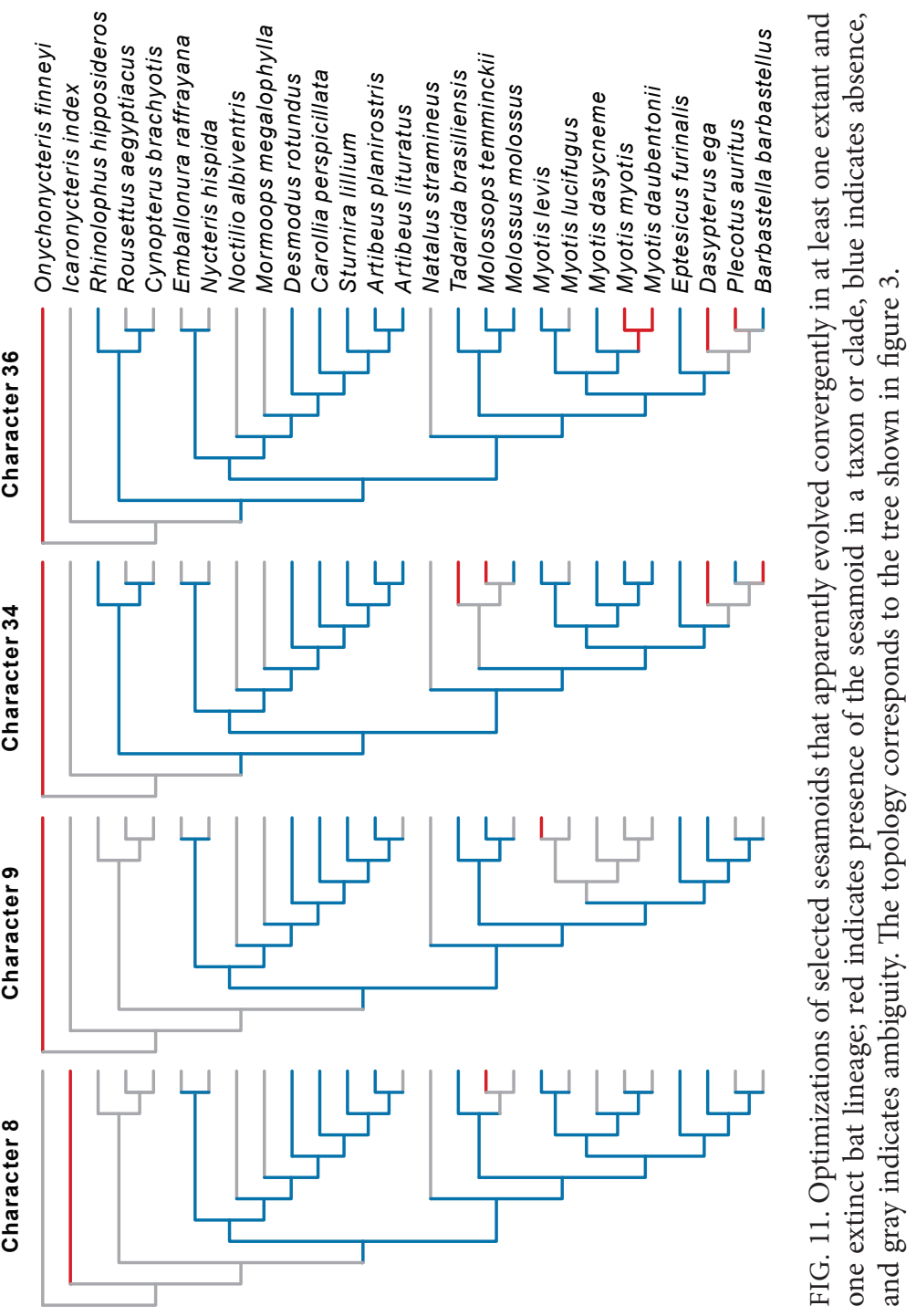




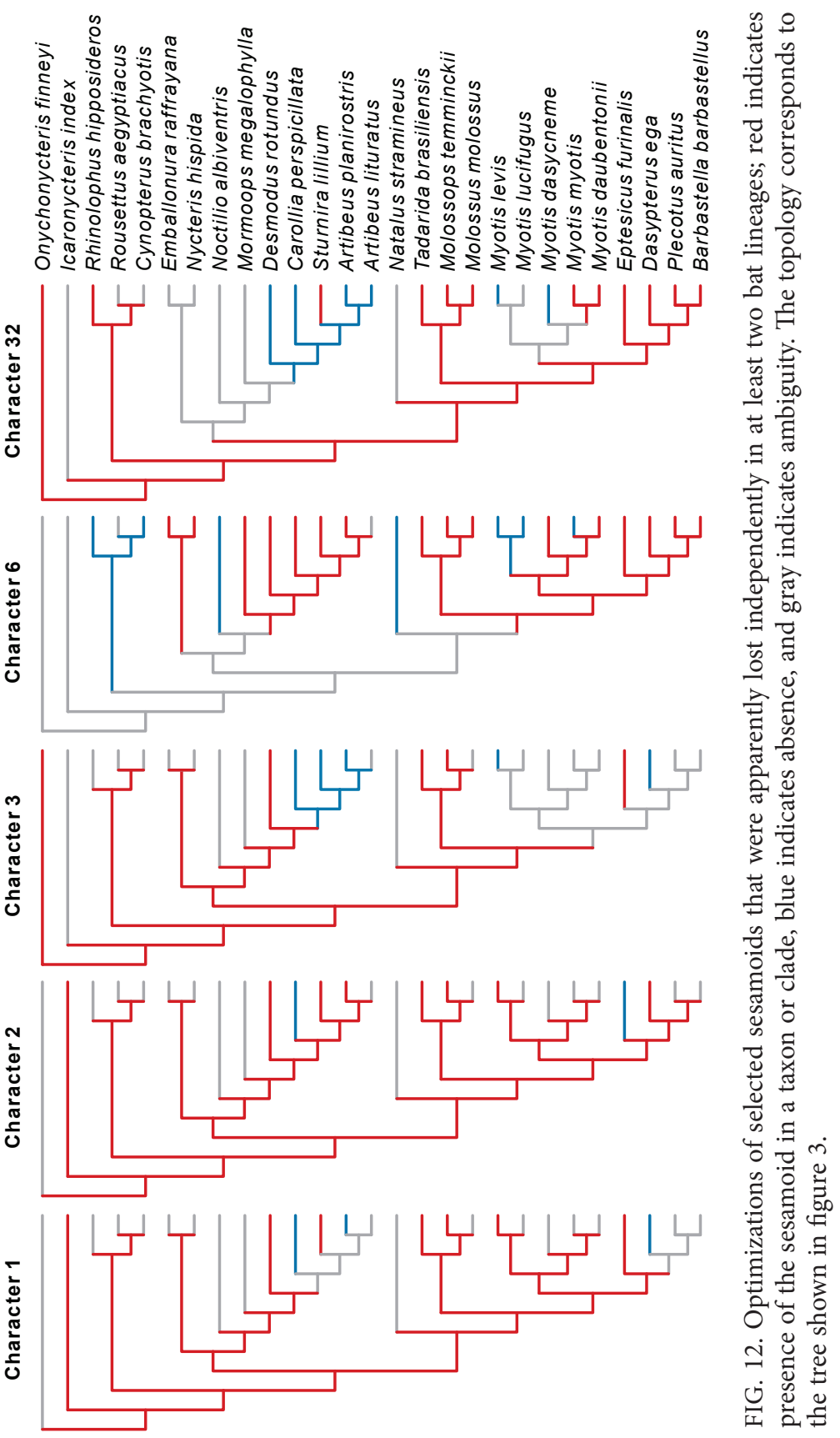


unconfirmed report that it may also be present in some rodents (Hardman, 1949). According to our optimization (fig. 12), the presence of an ulnar patella is plesiomorphic for crown Chiroptera, already present in Icaronycteris (fig. 2) and probably also in Onychonycteris. In contrast to comments made by Jepsen (1966: 3) in his original description of Icaronycteris, where he reported "no trace of sesamoid at end of ulna," we interpreted the bony structure present on the distal end of the humerus as an ulnar patella (fig. 2). The ulnar patella was apparently independently lost in at least three bat lineages including those leading to Carollia perspicillata, Artibeus planirostris (Phyllostomidae), and Dasypterus ega (Vespertilionidae; fig. 12).

Developmental and injury data from humans provide some clues as to the possible evolutionary origins of the ulnar patella. Gunn (1928) and Habbe (1942) were the first to report cases of "patella cubiti" in humans, a condition in which the olecranon is separated from the ulna and the resulting smaller element-the patella cubiti-appears morphologically and positionally similar to the ulnar patella of bats (fig. 13). This anomaly was long treated by the medical profession as the consequence of an injury or an acquired pseudarthrosis (nonmending bone fracture; e.g., Kjelland, 1945; Levine, 1950; see also Mittal et al., 2014). More recently, however, Winter et al. (2006) reported a patella cubiti case but noted that the separated fragment had a smooth surface, suggesting that it is probably the result of a failure in the fusion between the ossification center of olecranon and the rest of ulna during embryogenesis (see also Ahlgren and Rydholm, 1975). A similar developmental pathway, albeit one that has become fixed rather than anomalous, might be responsible for the occurrence of an ulnar patella in bats.

The observations of Winter et al. (2006) seem to agree with the traction epiphysis hypothesis proposed originally by Parsons (1904): the ulnar patella may be homologous to the unfused epiphysis of the ulna. Supporting this hypothesis, Barnet and Lewis (1958) observed that the presence of an ulnar patella was linked to the absence of an olecranon process (i.e., resulting in an abruptly terminated ulna with no proximal projection beyond the joint) in many avian species. Recently, Koyama et al. (2010) have shown that the ulna of mutant mouse embryos lacking all Hox 11 paralogous genes lacks an olecranon process. In its place, an ectopic ulnar patella-like structure associated with the tendon of $\mathrm{m}$. triceps forms in these mice. However, when Koyama et al. (2010) analyzed olecranon development in wild mouse embryos, they found that it did not originate from an independent ossification center that subsequently fused to the ulna; rather, the olecranon formed from a lengthening of the proximal end of the ulna. This developmental process is contrary to what would be expected under the traction epiphysis hypothesis. In any case, interpretations of bony crests and sculpturing resulting from the putative attachment of sesamoids to the main body of long bones (and vice versa) have been frequently posited in the literature (Parsons, 1904; Pearson and Davin, 1921a, 1921b; Bizarro, 1921; Hogg, 1980; Hutchinson, 2002; Hall, 2005; Koyama. 2010; Eyal et al., 2015). Regardless of the developmental process involved, some of the Hox11 paralogous genes appear responsible for giving rise to either an olecranon process on the ulna when the gene is expressed, or a separated ulnar patella-like structure when the gene is deactivated (Koyama et al., 2010). Changes in Hox 11 genes thus seem to be implicated in the evolutionary acquisitions and losses of the ulnar patella in mammals. The role of Hox genes in sesamoid gain and loss was previously 

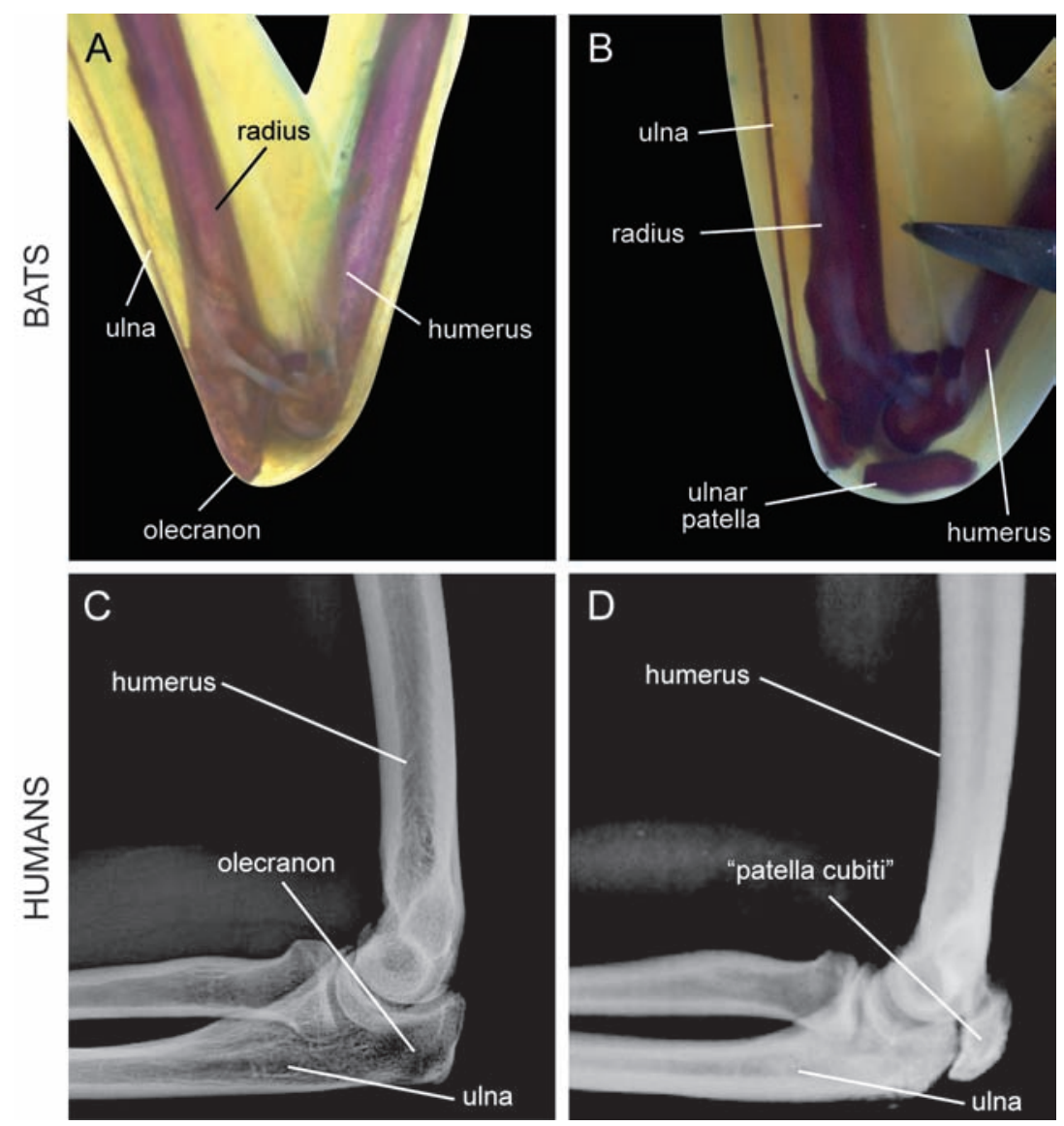

FIG. 13. Comparison between the elbow of bats (A, left elbow of Dasypterus ega; B, left elbow of Molossops temminkii) and humans (C, D, modified from Mittal et al., 2014), including either an olecranon (A, C) or an ulnar patella $(\mathbf{B}, \mathbf{D})$. The possible homology between the ulnar patella in bats and the anomalous "patella cubiti" in humans is shown.

discussed by Vickaryous and Olson (2007), and more research is clearly needed to determine the role(s) of these genes in general in sesamoid evolution in bats and other tetrapods.

The reduced olecranon process paired with the presence of an ulnar patella in most bat species suggests that $\mathrm{m}$. triceps, whose insertion occurs via the ulnar patella, may be adapted to produce alternative rapid or powerful extension of the forearm depending on the stage in the wingbeat cycle and, therefore, of the joint angle (Vaughan, 1959; Norberg, 1972; Alexander and Dimery, 1985). Electromyographic studies have shown that $\mathrm{m}$. triceps is active primarily as the wing is extended at the top of the upstroke, but the contraction of this muscle continues during the first half of the downstroke (Altenbach, 1979). M. triceps apparently extends the forearm rapidly at the start of the downstroke in order to achieve the maximum thrust and lift from the wingbeat cycle (Vaughan, 1959). This muscle is also important in quick maneuvers that require rapid wing extension (Vaughan, 1959; Maniakas and Youlatos, 2012). Konow et al. (2015) showed that, in Carollia perspicillata, elbow flexion at the end of the downstroke actively 
stretches the triceps tendon, which then recoils elastically during the upstroke. This springlike mechanism decreases the energy that extensor muscles must expend during upstroke (Konow et al., 2015). The ulnar patella may be acting as a protection for the insertion tendon of $\mathrm{m}$. triceps while it passes over bony prominences at the elbow during rapid wing-extension maneuvers. However, Hermanson and Altenbach (1983) showed that the long and lateral heads of m. triceps in Antrozous pallidus are active only during the upstroke, when the elbow joint is flexed, thus contradicting the hypothetical role of $\mathrm{m}$. triceps as elbow extensor. The mechanics of joint and tendon function in bats is clearly complex, and additional biomechanical analyses including a wider taxonomic sampling are necessary in order to clarify the function of $\mathrm{m}$. triceps and the ulnar patella.

PAtella. The patella (= kneecap; char. 25) in mammals is associated with the tendon of the m. vastus medialis of the quadriceps complex. The function typically assigned to the patella is to protect the $\mathrm{m}$. quadriceps tendon and the underlying patelo-femoral cartilage (Mottershead, 1988), and to hold the tendon further from the joint, thus enhancing the lever system of the knee (e.g., Regnault et al., 2014; Samuels et al., 2017). Although the vastus muscle complex in bats is not differentiated into separate muscle masses (there is only one $\mathrm{m}$. vastus rather than separate $\mathrm{m}$. vastus medialis, $\mathrm{m}$. vastus intermedius, and $\mathrm{m}$. vastus lateralis), a bony patella is present in almost all known taxa (Vaughan, 1959; Simmons and Geisler, 1998) with the exception of Pteropus (Smith et al., 1995; see below). The patella was present in all the bats we sampled including fossils (figs. 1, 2, 6, 9), and in our dissections of extant taxa the patella was found to be surrounded by tendinous connective tissue as reported by Vaughan (1959). However, both our extant specimen sample as well as that observed by Vaughan (1959) was restricted to yangochiropteran species.

Smith et al. (1995) analyzed the variation in the patella and associated tissues in 13 bats including 7 members of the family Pteropodidae. In nonpteropodid bats, they observed a bony patella surrounded with tendinous connective tissue just as we found in our study. In three pteropodid species (Haplonycteris fischeri, Cynopterus brachyotis, Rousettus aegyptiacus), Smith et al. (1995) reported a bony patella surrounded by fibrocartilage and hyaline cartilage, but in the remaining four species, all belonging to the genus Pteropus, the cartilaginous tissue did not contain any bone structure or evidence of mineralization (Smith et al., 1995). According to the authors, the disposition of this cartilage tissue differs from that in the fibrocartilage patella observed in Macropodidae (i.e., kangaroos and wallabies; Holladay et al., 1990), which occurs in these taxa as a discrete pad that mimics a bony patella in position, size, and shape. In contrast to this arrangement, the cartilage tissue in Pteropus is organized as diffuse layers that constitute a relatively undefined structure that is not visible to the naked eye upon dissection. Smith et al. (1995) could not explain this difference in functional terms. These authors suggested that it might be informative to analyze the patella in species with different locomotor habits such Desmodus rotundus, which uses quadrupedal locomotion in addition to flight; however, we did not observe any peculiarity in the patella of this species. Instead, we did find an interesting difference in molossids (Tadarida brasiliensis and Molossops temminckii), which have a suprapatella proximal to the patella, manifested as either a single structure or divided into three adjacent elements (char. 24; fig. 6). 
Although many aspects of knee morphology are conserved across Tetrapoda, the structure of the patella shows a notable variation. Anurans, some lizards and birds, and most marsupial mammals have a patella that is composed of fibrocartilage rather than bone (Holladay et al., 1990; Reese et al., 2001; Regnault et al., 2014; Samuels et al., 2017; Abdala et al., 2017; Inamassu et al., 2017). Within crown Mammalia, a bony patella likely evolved between four to six times, and within Eutheria, the bony patella had been lost in three independent lineages: Cetacea (represented by Tursiops truncatus), Sirenia (represented by Trichechus manatus), and Chiroptera (represented by Pteropus) (Samuels et al., 2017). In the former two taxa, the distal hind limb and therefore the patella have been lost during the evolution of adaptations for an aquatic lifestyle. The cause of loss of ossification of the patella in Pteropus remains unknown.

Eyal et al. (2015) demonstrated that the patella in mouse embryos originates from a distinct lineage of progenitor cells in the anterodistal surface of the femur, and that posteriorly the patella separates from the femur by the formation of the joint, which is regulated by mechanical load (i.e., this process depends on muscle contractions). These observations appear to refute the epiphysis traction hypothesis of Parsons (1904), in which sesamoids are thought to arise within the tendinous tissue. In contrast, the findings of Eyal et al. (2015) seem to support a contrary hypothesis proposed by Pearson and Davin (1921a, 1921b) who suggested that sesamoids arise from bony processes that become separated from the main bone by a mechanism then unknown. As noted above, a similar mechanism could be acting in the elbow to produce the ulnar patella; therefore, bats constitute interesting study organisms for future work on the ontogeny of major sesamoid elements.

RADIAL SESAMOID AND PISIFORM. The radial sesamoid (char. 10) is located on the radial side of the ventral surface of the wrist, and this element is the origin of $\mathrm{m}$. abductor digiti quintii in many bat species (table 1; fig. 5). This muscle helps stabilize metacarpal V against air pressure created during the downstroke, and is also a weak flexor of digit V, thus helping to regulate camber in the distal part of the wing (Vaughan, 1959; Norberg, 1972). In contrast, the pisiform (char. 11; fig. 5) is also located on the ventral surface of the wrist, but on the ulnar side associated with the distal row of carpals. The distal end of the pisiform is strongly bound by fascia to the proximal end of the metacarpal $\mathrm{V}$, while the proximal end of the pisiform rests against the ventral surface of the trapezium and is bound to the ventral surface of the carpus by connective tissue, allowing little dorsoventral movement (Vaughan, 1959). The pisiform is attached to the radial sesamoid by a broad ligament, the flexor retinaculum. The radial sesamoid is, in turn, the insertion point of the m. abductor pollicis longus. In most mammals, this muscle is inserted into metacarpal I and functions as an abductor of the thumb, but in bats the action is exerted on metacarpal V, via the radial sesamoid and the pisiform (Vaughan, 1959; Noberg, 1972). The action of $\mathrm{m}$. abductor pollicis longus, similar to that of $\mathrm{m}$. abductor digiti quinti, consists in reinforcing the fifth carpometacarpal joint during the downstroke, thus avoiding the dorsal extension of digit V. Additionally, the pisiform serves as an insertion point for the m. flexor carpi ulnaris, which acts as a posterior flexor of digit V (Vaughan, 1959; Norberg, 1972). Even though the radial sesamoid/flexor retinaculum/pisiform complex performs some distinct functions in bats, it also plays a role shared with other tetrapods to form the 
carpal tunnel through which the flexor tendons of the forelimb cross the carpal joint and become organized, thereby avoiding the bowstringing of tendons and/or adding to their slippage (Haines, 1950; Fontanarrosa and Abdala, 2014, 2016). This role may be of particular importance in bats because of the conspicuous system of ropelike tendons that must cross the wrist in the handwing. Both a radial sesamoid and a pisiform are present in all the extant bat species we examined, in Icaronycteris, and possibly also in Onychonycteris (fig. 9), and hence the presence of both elements appears to be plesiomorphic for bats.

Parafibula. The parafibula (char. 29; figs. 1, 2, 6) is located on the proximal end of the fibula within the lateral collateral ligament that connects the femur and the tibia. A fibula with a hypertrophied epiphysis apparently resulting from a fused parafibula has been identified in several extant and extinct mammals (e.g., Barnet and Lewis, 1958; Li and Luo, 2006, Yuang et al., 2013). The parafibula is present as a separate sesamoid in the extinct and most extant bat species observed, with the exception of Myotis levis and Eptesicus furinalis. We found a parafibula in species with a complete fibula (e.g., Tadarida brasiliensis) as well as in species with a reduced fibula (e.g., Sturnira lilium) bearing a thin epiphysis (fig. 6). The absence of a parafibula in some species with a reduced fibula (i.e., in Myotis and Eptesicus) suggests that the parafibula can be lost without any trace of fusion with another bone element, with its reduction occurring either prior to or coincident with fibular reduction. This suggests that the traction epiphysis hypothesis of sesamoid loss (Parsons, 1904) may not be applicable to all cases of sesamoid loss, and that other mechanisms should be considered in future research and discussions.

\section{Sesamoids AND QuAdrupedal Locomotion}

We hypothesize that the relatively high number of sesamoids recorded in molossids (22-23 sesamoids) and vampires (20) may be associated with quadrupedal locomotion in these taxa. The common vampire bat Desmodus rotundus, a highly specialized sanguivorous species, combines a symmetrical walk with a particular asymmetrical bounding gait at higher speeds, allowing it to follow prey that move during a feeding event (Riskin et al., 2006). Desmodus was the only sampled taxon found to have a cyamella (sesamoid in the m. popliteus) and fabellae (pair of sesamoids in the m. gastrocnemius). Molossids are agile flyers but are also nimble crawlers that use quadrupedal locomotion in their roosts, having a particular wing-folding mechanism that allows them to compactly fold the long wings in order to avoid membrane damage during quadrupedal locomotion (Vaughan, 1966; Schutt and Simmons, 2006). The sesamoids present exclusively in Molossidae (suprapatella and ventral sesamoids on carpus and metatarsus) might be related to this type of locomotion. Chadwick et al. (2017) showed that the patellar tendon of the ostrich, which typically has two patellae (Macalister, 1864), has the potential for developing multiple patellae based solely upon mechanical stimuli. In a similar way, the possible distinctive loading and stress patterns of the patellar tendon in molossids might be favoring the presence of one or more suprapatellae in these taxa. Differences in the properties of tendons playing different functional roles-e.g., those that power locomotion versus those that act to limiting excessive flexion of joints-have been reported in other vertebrates (e.g., Zhang et al., 2017), and the same may apply to sesamoids. Thus, the rela- 
tively large number of sesamoids in molossids and Desmodus might result from the additional functional demands resulting from regularly employing two very different types of locomotion (i.e., flapping flight vs. quadrupedal cursorial locomotion), a hypothesis first proposed by Reyes-Amaya et al. (2017). In this context, it would be useful for future studies to assess the sesamoid endowment of other quadrupedal bat species such Mystacina tuberculata (Mystacinidae) and the two other species of vampires (Diaemus youngi and Diphylla ecaudata) as well as additional molossid species. Sturnira lilium (Phyllostomidae) also shows a high number of sesamoids (20). Based on its sesamoid endowment, as well as the lack of a tail membrane and the notable hind limb dexterity that this species displays when captured, we hypothesize that $S$. lilium might be specialized for quadrupedal locomotion along internal branches of small trees and shrubs while searching for fruit not displayed on the outer branches. Additional investigations of phyllostomids with different locomotor habits might provide further insight into the evolution of sesamoids in this diverse group.

\section{Sesamoids in Fossil Bats}

We positively identified 10 and 12 sesamoids (or sets of sesamoids) in Onychonycteris and Icaronycteris, respectively (table 4, figs. 1,2). Five of these, the medial ventral sesamoid on the metacarpo-phalangeal joint I (char. 20), the lateral ventral sesamoid on the metacarpo-phalangeal joint I (char. 21), the femoral patella (char. 25), the parafibula (char. 29), and the pedal ossa sesamoidea phalangis (char. 43) were identified in both taxa (table 4). No sesamoid was exclusively present in the fossil taxa. Interestingly, the two fossil bats examined in our study bear a resemblance to molossid bats in terms of their complements of sesamoids. Onychonycteris shares eight sesamoids with Tadarida and Molossops, two of which were almost exclusively found in these species: the elbow sesamoid in the origin of the $\mathrm{m}$. supinator and $\mathrm{m}$. extensor digitorum communis (char. 3), and the sesamoid dorsal to the navicular (char. 34). We hypothesize that this apparent case of convergence may reflect a certain degree of quadrupedal locomotion in Onychonycteris (e.g., along tree branches). Both the presence of claws on all wing digits and the limb proportions of Onychonycteris suggest that this extinct bat was more similar to other climbing mammals than any other known bat (Simmons et al., 2008). The other Eocene bat that we sampled, Icaronycteris, shares 11 sesamoids with Tadarida and Molossops, of which one sesamoid is exclusively shared in our sample with the latter taxon, namely, the dorsal sesamoid of the wrist, located between the scaphocentralolunatum and the cuneiform (char. 8). It is possible that the presence of these sesamoids in these ancient bats is indicative of similar diverse locomotor habits, but further evaluation of such hypotheses is beyond the scope of the present study.

\section{CONCLUSIONS}

Bats possess a very large complement of sesamoids (as many as 23 in a single species) with a large amount of variation among taxa-46 different sesamoids (or sets of sesamoids) occur in Chiroptera. Sesamoid presence is relatively balanced between forelimb and hind 
limb; however, when the joints of both limbs are compared, sesamoids are more numerous in the knee than in the elbow, and more so in the manual than in the pedal autopodium. The elbow and knee joints are characterized by embedded sesamoids, while in the autopodial joints we found that supporter and glide sesamoids are more frequent. In the forelimb, a majority of the sesamoids are found in the handwing, possibly associated with the evolution of a conspicuous tendinous system that distally replaced heavy muscle bellies in bats; this system evolved perhaps in response to the aerodynamic need for decreased weight near the wing tip, which in turn facilitates a low inertial power, one of the components of total aerodynamic power required for flight.

All of the sesamoids widely distributed among bat taxa were already present in at least one of the two Eocene species included in our study, indicating that their presence and possibly their function(s) have remained stable at least since the Early Eocene. Most of these ubiquitous sesamoids are plesiomorphic for Chiroptera within the framework of what is known about mammalian sesamoid distributions, with the notable exception of the ulnar patella. This structure, which is apparently absent in other mammals, is known from other tetrapods and hence represents either an evolutionary reversal (if present in the ancestor of tetrapods) or independent acquisitions in particular tetrapod lineages. Other sesamoids are seemingly exclusive to chiropteran clades, although this may be challenged in the future with additional sampling within a wider taxonomic framework. The sesamoid similarities between the two ancient bats and extant molossids may reflect similar functional constraints; however, more work on the functional roles of sesamoids in general, and sesamoids shared among species in particular, will be necessary before we can speculate further on the evolutionary origins and roles of these structures. Most notably, detailed biomechanical studies are needed to test hypotheses of the link between form and function of sesamoids in the chiropteran postcranium. The significant abundance and variability of sesamoids in Chiroptera suggest that bats may provide an excellent model system for enhancing understanding of the function, developmental basis and mechanical significance of sesamoids. This study constitutes an initial step in that direction.

\section{ACKNOWLEDGMENTS}

We thank to Pablo Teta and Sergio Lucero (MACN), Fernando Lobo (IBIGEO), Chris Norris (YPM), Neil Duncan (AMNH Mammalogy), and Ruth O'Leary (AMNH Paleontology) for access to specimens in their care. L.I.A. thanks Miriam Vera, Jessica Fratani, and Ana Dupport Bru for their help during the staining process. Special thanks to Sharon Swartz and one anonymous reviewer for their very helpful and substantive comments on an earlier version of this manuscript. Funding for this study was provided by Consejo Nacional de Investigaciones Científicas y Técnicas (Grant PIP-CONICET 389 to V.A. [corresponding author]and Ph.D. Fellowship to L.I.A.), Agencia Nacional de Promoción Científica y Tecnológica (Grant PICT 2016-2772 to V.A., and PICT 2015-2389 and 2016-3682 to N.P.G.), and the United States National Science Foundation (research grants DEB-9873663, EF-062811, and DEB-0949859 to N.B.S.). 


\section{REFERENCES}

Abdala, V., M. Vera, and M.L. Ponssa. 2017. On the presence of the patella in frogs. Anatomical Record 300: 1747-1755.

Adriaens, D., and W. Verraes. 1998. Ontogeny of the osteocranium in the African catfish, Clarias gariepinus Burchell (1822) (Siluriformes: Clariidae): ossification sequence as a response to functional demands. Journal of Morphology 235: 183-237.

Ahlgren, S.A., and A. Rydholm. 1975. Patella cubiti: report of an operated case. Acta Orthopaedica Scandinavica 46: 931-933.

Alexander, R. 1967. The functions and mechanisms of the protrusible upper jaws of some acanthopterygian fish. Journal of Zoology 151: 43-64.

Alexander, R. 1984. Elastic energy stores in running vertebrates. American Zoologist 24: 85-94.

Alexander, R. McN., and N. Dimery. 1985. The significance of sesamoids and retro-articular processes for the mechanics of joints. Journal of Zoology 205: 357-371.

Altenbach, J.S. 1979. The locomotor morphology of the vampire bat, Desmodus rotundus. American Society of Mammalogists, Special Publication 6: 1-137.

Amador, L.I., R.L. Moyers-Arévalo, F.C. Almeida, S.A. Catalano, and N.P. Giannini. 2018. Bat systematics in the light of unconstrained analyses of a comprehensive molecular supermatrix. Journal of Mammalian Evolution 25: 37-70.

Barnet, C.H., and O.J. Lewis. 1958. The evolution of some traction epiphyses in birds and mammals. Journal of Anatomy 4: 593-601.

Bianchi, S., I.F. Abdelwahab, A. Zwass, and L. Molini. 1993. Fractures of the sesamoid bone of thumb. Bulletin of the Hospital for Joint Diseases 53: 7-10.

Bizarro, A.H. 1921. On sesamoid and supernumerary bones of the limbs. Journal of Anatomy 55: 256-268.

Bland, Y.S., and D.E. Ashhurst. 1997. Fetal and postnatal development of the patella, patellar tendon and suprapatella in the rabbit; changes in the distribution of the fibrillar collagens. Journal of Anatomy 190: 327-342.

Carlsöö, S. 1982. The effect of vibration on the skeleton, joints and muscles. Applied Ergonomics 13 (4): 251-258.

Chadwick, K.P., S. Regnault, V. Allen, and J.R. Hutchinson. 2014. Three-dimensional anatomy of the ostrich (Struthio camelus) knee joint. PeerJ 2: e706.

Chadwick, K.P., S.J. Shefelbine, A.A. Pitsillides, and J.R. Hutchinson. 2017. Finite-element modelling of mechanobiological factors influencing sesamoid tissue morphology in the patellar tendon of an ostrich. Royal Society Open Science 4: 170133.

Cuff, A.R., et al. 2016. The scaling of postcranial muscles in cats (Felidae) I: forelimb, cervical, and thoracic muscles. Journal of Anatomy 229: 128-141.

Cypher, J.L. 1996. Phylogenetic analysis of the order Chiroptera using carpal morphology. Master's thesis, Eastern Michigan University, Ypsilanti, Michigan.

DeCamp, C.E. 2016. Brinker, Piermattei and Flo's Handbook of small animal orthopedics and fracture repair, 5th ed. St. Louis: Elsevier B.V.

Evans, H.E., and A. De Lahunta. 2013. Miller's Anatomy of the dog (EBook), 4th ed. St. Louis: Elsevier Health Sciences, 850 pp.

Eyal, S., et al. 2015. On the development of the patella. Development 142: 1831-1839.

Fontanarrosa, G., and V. Abdala. 2014. Anatomical analysis of the lizard carpal bones in the terms skilled manual abilities. Acta Zoologica 95: 249-263. 
Fontanarrosa, G., and V. Abdala. 2016. Bone indicators of grasping hands in lizards. PeerJ 4: e1978.

Gibeault, J.B., P. Saba, H. Hoenecke, and A. Graham. 1989. The sesamoids of the metacarpophalangeal joint of the thumb: an anatomical and clinical study. Journal of Hand Surgery: British and European 14: $244-247$.

Goldberg, I., and H. Nathan. 1987. Anatomy and pathology of the sesamoid bones. International Orthopaedics 11: 141-147.

Goloboff, P.A., J.S. Farris, and K.C. Nixon. 2008. TNT, a free program for phylogenetic analysis. Cladistics 24: 774-786.

Gunn, G. 1928. Patella cubiti. British Journal of Surgery 15: 612-615.

Habbe, J.E. 1942. Patella cubiti. A report of four cases. American Journal of Roentgenology 48: 513-526.

Haines, R.W. 1940. Note on the independence of sesamoid and epiphysial centres of ossification. Journal of Anatomy 75: 101-105.

Haines, R.W. 1950. The flexor muscles of the forearm and hand in lizards and mammals. Journal of Anatomy 84: 13-29.

Haines, R.W. 1969. Epiphyses and sesamoids. In C. Gans, and T.S. Parsons (editors), Biology of the Reptilia: 81-115. London: Academic Press.

Hall, B. 2005. Bones and cartilage: developmental and evolutionary skeletal biology. London: Elsevier B.V.

Hansen, C.A, and T.H. Peterson. 1987. Fracture of the thumb sesamoid bones. Journal of Hand Surgery 12: $269-270$.

Hardman, G.L. 1949. A sesamoid at the elbow analogous to the patella. British Journal of Radiology 22: 384-385.

Helal, B. 1981. The great toe sesamoid bones: the Lus or lost souls of Ushaia. Clinical Orthopaedics and Related Research 157: 82-87.

Hermanson, J.W., and J.S. Altenbach. 1983. The functional anatomy of the shoulder of the pallid bat, Antrozous pallidus. Journal of Mammalogy 64: 62-75.

Hockman, D., et al. 2008. A second wave of Sonic hedgehog expression during the development of the bat limb. Proceedings of the National Academy of Sciences 105: 16982-16987.

Hogg, D.A. 1980. A re-investigation of the centres of ossification in the avian skeleton at and after hatching. Journal of Anatomy 130 (4): 725-743.

Holladay, S.D., B.J., Smith, J.E. Smallwood, and L.C. Hudson. 1990. Absence of an osseous patella and other observations in Macropodidae stifle. Anatomical Record 226: 112-114.

Hudson, P.E., S.A. Corr, R.C. Payne-Davis, et al. 2011a. Functional anatomy of the cheetah (Acinonynx jubatus) hindimb. Journal of Anatomy 218: 363-374.

Hudson, P.E., et al. 2011b. Functional anatomy of the cheetah (Acinonynx jubatus) forelimb. Journal of Anatomy 218: 375-385.

Hutchinson, J.R. 2002. The evolution of hindlimb tendons and muscles on the line to crown-group birds. Comparative Biochemistry and Physiology A: Molecular and Integrative Physiology 133 (4): 10511056.

Inamassu, L.R., et al. 2017. Absence of bony patella in the white-eared opossum (Didelphis albiventris): morphology and diagnostic imaging. Anatomia, Histologia, Embryologia 46: 611-614.

Jepsen, G.L. 1966. Early Eocene bat from Wyoming. Science 154: 1333-1339.

Jerez, A., S. Mangione, and V. Abdala. 2010. Occurrence and distribution of sesamoid bones in squamates: a comparative approach. Acta Zoologica 91: 295-305.

Kawashima T., H. Takeishi, S. Yoshitomi, M. Ito, and H. Sasaki. 2007. Anatomical study of the fabella, fabellar complex and its clinical implications. Surgical and Radiologic Anatomy 29: 611-616. 
Kim, H.T., W.M. Olson, and B.K. Hall. 2009. Effects of hind limb denervation on the development of appendicular ossicles in the dwarf African clawed frog, Hymenochirus boettgeri (Anura: Pipidae). Acta Zoologica 90: 352-358.

Kjelland, P.M. 1945. A rare anomaly in the elbow: patella cubiti. Acta Radiologica 26: 491-496.

Konow, N., J.A. Cheney, T.J. Roberts, J.R.S. Waldman, and S.M. Swartz. 2015. Spring or string: does tendon elastic action influence wing muscle mechanics in bat flight? Proceedings of the Royal Society B, Biological Sciences 282: 20151832.

Koyama, E., et al. 2010. Hox11 genes establish synovial joint organization and phylogenetic characteristics in developing mouse zeugopod skeletal elements. Development 137: 3795-3800.

Le Minor, J.M. 1987. Comparative anatomy and significance of the sesamoid bone of the peroneus longus muscle (os peroneum). Journal of Anatomy 151: 85-99.

Le Minor, J.M. 1994. The sesamoid bone of musculus abductor pollicis longus (os radiale externum or prepollex) in primates. Cells Tissues Organs 150: 227--31.

Levine, M.A. 1950. Patella cubiti. Journal of Bone and Joint Surgery 32: 686-687.

Li, G., and Z.-X. Luo. 2006. A Cretaceous symmetrodont therian with some monotreme-like postcranial features. Nature 439: 195-200.

Macalister, A. 1864. On the anatomy of the ostrich (Struthio camelus). Proceedings of the Royal Irish Academy (1836-1869) 9: 1-24.

Macalister, A. 1872. The myology of the Cheiroptera. Philosophical Transactions of the Royal Society of London 162: 125-171.

Maisano, J.A. 2002. Postnatal skeletal ontogeny in Callisaurus draconoides and Uta stansburiana (Iguania: Phrynosomatidae. Journal of Morphology 251: 114-139.

Maniakas, I., and D. Youlatos. 2012. Myological adaptations to fast enduring flight in European freetailed bats, Tadarida teniotis (Molossidae, Chiroptera). Italian Journal of Zoology 79: 574-581.

McBryde, A.M., Jr., and R.B. Anderson. 1988. Sesamoid foot problems in the athlete. Clinics in Sports Medicine 7: 51-60.

Mellado, J.M., et al. 2003. Accessory ossicles and sesamoid bones of the ankle and foot: imaging findings, clinical significance and differential diagnosis. European Radiology 13: 164-177.

Mittal, R., V.S. Kumar, and T. Gupta. 2014. Patella cubiti: a case report and literature review. Archives of Orthopaedic and Trauma Surgery 134: 467-471.

Mittlmeier, T., and P. Haar. 2004. Sesamoid and toe fractures. Injury 35: 87-97.

Montero, R., J.D. Daza, A.M. Bauer, and V. Abdala. 2017. How common are cranial sesamoids among squamates? Journal of Morphology 278: 1400-1411.

Mottershead, S. 1988. Sesamoid bones and cartilages: an enquiry into their function. Clinical Anatomy 1: 59-62.

Müller, G.B. 2003. Embryonic motility: environmental influences and evolutionary innovation. Evolution and Development 5: 56-60.

Müller, G.B., and G.P. Wagner. 1991. Novelty in evolution: restructuring the concept. Annual Review of Ecology and Systematics 22: 229-256.

Newman, S.A., and G.B. Müller. 2000. Epigenetic mechanisms of character origination. Journal of Experimental Zoology Part A: Ecological Genetics and Physiology 288: 304-317.

Norberg, U.M. 1972. Functional osteology and myology of the wing of the dog-faced bat Rousettus aegyptiacus (É. Geoffroy) (Mammalia Chiroptera). Zeitschrift für Morphologie und Okologie der Tiere 73: 1-44.

Norberg, U.M. 1990. Vertebrate flight: mechanics, physiology, morphology, ecology and evolution. Berlin: Springer-Verlag, $291 \mathrm{pp}$. 
Norberg, U.M., and J.M.V. Rayner. 1987. Ecological morphology and flight in bats (Mammalia; Chiroptera): wing adaptations, flight performance foraging strategy and echolocation. Philosophical Transactions of the Royal Society of London B 316: 335-427.

Nussbaum, R.A. 1982. Heterotopic bones in the hind limbs of frogs of the families Pipidae, Ranidae and Sooglossidae. Herpetologica 38: 312-320.

Olson, W. 2000. Phylogeny, ontogeny, and function: extraskeletal bones in the tendons and joints of Hymenochirus boettgeri (Amphibia: Anura: Pipidae). Zoology 103: 15-24.

Otero, T., and J.M. Hoyos. 2013. Sesamoid elements in lizards. Herpetological Journal 23: 105-114.

Oxnard, C.E. 1971. Tensile forces in skeletal structures. Journal of Morphology 134: 425-436.

Panyutina, A.A., L.P. Korzun, and A.N. Kuznetsov. 2015. Flight of mammals: from terrestrial limbs to wings. Cham, Germany: Springer, $301 \mathrm{pp}$.

Parsons, F.G. 1904. Observations on traction epiphyses. Journal of Anatomy and Physiology 38: 248-258.

Pearson, K., and A.G. Davin. 1921a. On the sesamoids of the knee joint. Part I. Man. Biometrika 3: 133-175.

Pearson, K., and A.G. Davin. 1921b. On the sesamoids of the knee-joint. Part II. Evolution of the sesamoids. Biometrika 13: 350-400.

Pomikal, C., and Streicher, J. 2010. 4D-analysis of early pelvic girdle development in the mouse (Mus musculus). Journal of Morphology 271: 116-126.

Ponssa, M.L., J. Goldberg, and V. Abdala. 2010. Sesamoids in anurans: New data, old issues. Anatomical Record 293: 1646-1668.

Reese, S., U.R. Pfuderer, H. Bragulla, K. Loeffler, and K.D. Budras. 2001. Topography, structure and function of the patella and the patelloid in marsupials. Anatomia, Histolologia, Embryologia 30: 289-294.

Regnault, S., A.A. Pitsillides, and J.R. Hutchinson. 2014. Structure, ontogeny and evolution of the patellar tendon in emus (Dromaius novaehollandie) and other palaeognath birds. PeerJ 2: e711.

Regnault S., M.E.H. Jones, A.A. Pitsillides, and J.R. Hutchinson. 2016. Anatomy, morphology and evolution of the patella in squamate lizards and tuatara (Sphenodon punctatus). Journal of Anatomy 228: 864-876.

Regnault, S., J.R. Hutchinson, and M.E. Jones, 2017. Sesamoid bones in tuatara (Sphenodon punctatus) investigated with $\mathrm{X}$ ray microtomography, and implications for sesamoid evolution in Lepidosauria. Journal of Morphology 278: 62-72.

Retterer, É., and A. Lelièvre. 1911. Des sésamoides vésiculo-fibreux des mammifères. Comptes Rendus des Séances de la Société de Biologie et de ses Filiales 71: 5-8.

Reyes-Amaya, N., A. Jerez, and D. Flores. 2017. Morphology and postnatal development of lower hind limbs in Desmodus rotundus (Chiroptera: Phyllostomidae): A Comparative Study. Anatomical Record 300: 2150-2165.

Richardson, G.E. 1999. Hallucal sesamoid pain: causes and surgical treatment. Journal of the American Academy of Orthopaedic Surgeons 7: 270-278.

Riskin, D.K., S. Parsons, W.A. Schutt, G.G. Carter, and J.W. Hermanson. 2006. Terrestrial locomotion of the New Zealand short-tailed bat Mystacina tuberculata and the common vampire bat Desmodus rotundus. Journal of Experimental Biology 209: 1725-1736.

Romankowowa, A. 1961 The sesamoid bones of the autopodia of bats. Acta Theriologica 5: 125-140.

Romer, A.S. 1956. Osteology of the reptiles. Chicago: University of Chicago Press, 772 pp.

Samuels, M.E., S. Regnault, and J.R. Hutchinson. 2017. Evolution of the patellar sesamoid bone in mammals. PeerJ 5: e3103. 
Sarin, V.K., G.M. Erickson, and N.J. Giori. 1999. Coincident development of sesamoid bones and clues to their evolution. Anatomical Record 257: 174-180.

Schutt, W.A., and N.B. Simmons. 2006. Quadrupedal bats: form, function and phylogeny. In A. Zubaid, G. McCracken, and T. Kunz (editors), Functional and evolutionary ecology of bats: 15-159. Oxford: Oxford University Press.

Sears, K.E., R.R. Behringer, J.J. Rasweiler, and L.A. Niswander. 2006. Development of bat flight: morphologic and molecular evolution of bat wing digits. Proceedings of the National Academy of Sciences of the United States of America 103: 6581-6586.

Simmons, N.B. 1994. The case for chiropteran monophyly. American Museum Novitates 3103: 1-54.

Simmons, N.B., and J.H. Geisler. 1998. Phylogenetic relationships of Icaronycteris, Archaeonycteris, Hassianycteris, and Palaeochiropteryx to extant bat lineages, with comments on the evolution of echolocation and foraging strategies in Microchiroptera. Bulletin of the American Museum of Natural History 235: 143-169.

Simmons, N.B., K.L. Seymour, J. Habersetzer, and G.F. Gunnell. 2008. Primitive Early Eocene bat from Wyoming and the evolution of flight and echolocation. Nature 451: 818-821.

Sindberg, S.E. 1940. Fracture of a sesamoid of the thumb. Journal of Bone and Joint Surgery 22: 444-445. Skillern, P.G. 1915. On fractures of the sesamoid bones of the thumb. Annals Surgery 62: 297-301.

Smith, B.J., S.D. Holladay, and S.A. Smith. 1995. Patella of selected bats: Patterns of occurrence or absence and associated modifications of the quadriceps femoris tendon. Anatomical Record 242: 575-580.

Smith, T., J. Habersetzer, N.B. Simmons, and G.F. Gunnell. 2012. Systematics and paleobiogeography of early bats. In G.F. Gunnell, and N.B. Simmons (editors), Evolutionary history of bats: 23-66. Cambridge: Cambridge University Press.

Stener, B. 1963. Hyperextension injuries to the metacarpophalangeal joint of the thumb-rupture of ligaments, fracture of sesamoid bones, rupture of flexor pollicis brevis; An anatomical and clinical study. Acta Chirurgica Scandinavica 125: 275-293.

Streatfeild, T., and H.F. Griffiths. 1934. Fracture of sesamoid bones. Lancet 1: 1117.

Tsai, H.P., and C.M. Holliday. 2011. Ontogeny of the alligator cartilago transiliens and its significance for sauropsid jaw muscle evolution. PLoS One 6: e24935.

Vanden Berge, J.C., and R.W. Storer. 1995. Intratendinous ossification in birds: a review. Journal of Morphology 226: 47-77.

Vaughan, T.A. 1959. Functional morphology of three bats: Eumops, Myotis, Macrotus. University of Kansas Publications, Museum of Natural History 12: 1-153.

Vaughan, T.A. 1966. Morphology and flight characteristics of molossid bats. Journal of Mammalogy 47: 249-260.

Vaughan, T.A., and G.C. Bateman. 1970. Functional morphology of the forelimb of mormoopid bats. Journal of Mammalogy 51: 217-235.

Vera, M.C., M.L. Ponssa, and Abdala V. 2015. Further data on sesamoid identity from two anuran species. Anatomical Record 298: 1376-1394.

Vickaryous, M.K., and W.M. Olson. 2007. Sesamoids and ossicles in the appendicular skeleton. In B.K. Hall (editor), Fins and limbs: evolution, development and transformation: 323-341. Chicago: University of Chicago Press.

Walton, D.W., and G.M. Walton. 1970a. Post-cranial osteology of bats. In B.H. Slaughter and D.W. Walton (editors), About bats: a chiropteran symposium: 93-126. Dallas: Southern Methodist University Press. 
Walton, G.M., and D.W. Walton. 1970b. Post-cranial osteology of Chilonycteris psilotis. Revista de Biología Tropical 17: 147-164.

Wassersug, R.J. 1976. A procedure for differential staining of cartilage and bone in whole formalin-fixed vertebrates. Stain Technology 51:131-134.

Winter, M., T. Balaguer, and J. Tabutin. 2006. Bilateral patella cubiti. A case report. Journal of Bone and Joint Surgery 88: 415-417.

Wood, V.E. 1984. The sesamoid bones of the hand and their pathology. Journal of Hand Surgery 9: 261-264.

Yuang, C.-X., Q. Ji, Q.-J. Meng, A.R. Tabrum, and Z.-X. Luo. 2013. Earliest evolution of multituberculate mammals revealed by a new Jurassic fossil. Science 341: 779-783.

Zhang, R., et al. 2017. Macroscopic and microscopic analyses in flexor tendons of the tarsometatarsophalangeal joint of ostrich (Struthio camelus) foot with energy storage and shock absorption. Journal of Morphology. [doi: 10.1002/jmor.20772] 

All issues of Novitates and Bulletin are available on the web (http://digitallibrary. amnh.org/dspace). Order printed copies on the web from:

http://shop.amnh.org/a701/shop-by-category/books/scientific-publications.html or via standard mail from:

American Museum of Natural History-Scientific Publications Central Park West at 79th Street

New York, NY 10024

(2) This paper meets the requirements of ANSI/NISO Z39.48-1992 (permanence of paper). 